\title{
Perceptions of Parent-Initiated and Coach-Created Motivational Climate and their Influence on Youth Athlete Achievement Goal Orientation
}

\author{
Peter Kadushin \\ West Virginia University
}

Follow this and additional works at: https://researchrepository.wvu.edu/etd

\footnotetext{
Recommended Citation

Kadushin, Peter, "Perceptions of Parent-Initiated and Coach-Created Motivational Climate and their Influence on Youth Athlete Achievement Goal Orientation" (2011). Graduate Theses, Dissertations, and Problem Reports. 3315.

https://researchrepository.wvu.edu/etd/3315

This Thesis is protected by copyright and/or related rights. It has been brought to you by the The Research Repository @ WVU with permission from the rights-holder(s). You are free to use this Thesis in any way that is permitted by the copyright and related rights legislation that applies to your use. For other uses you must obtain permission from the rights-holder(s) directly, unless additional rights are indicated by a Creative Commons license in the record and/ or on the work itself. This Thesis has been accepted for inclusion in WVU Graduate Theses, Dissertations, and Problem Reports collection by an authorized administrator of The Research Repository @ WVU. For more information, please contact researchrepository@mail.wvu.edu.
} 
Perceptions of Parent-Initiated and Coach-Created Motivational Climate and their Influence on Youth Athlete Achievement Goal Orientation

Peter Kadushin, B.S.

Thesis submitted to the

College of Physical Activities and Sport Sciences

at West Virginia University in partial fulfillment of the requirements

for the degree of

Master of Science

in

Sport and Exercise Psychology

Damien Clement, Ph.D., ATC, Chair

Jack C. Watson II, Ph.D.

Ed Jacobs, Ph.D.

Department of Sport Sciences

Morgantown, WV

2011

Keywords: Motivational Climate; Achievement Goal Orientation; Youth Sports; Parents; Coaches 


\begin{abstract}
Perceptions of Parent-Initiated and Coach-Created Motivational Climate and their Influence on Youth Athlete Achievement Goal Orientation
\end{abstract}

Peter L. Kadushin

Researchers have investigated the relationship between motivational climate and achievement goal orientation in an effort to understand how to positively impact sport participants. However, little research has been done looking at the relationship between parents, coaches, and youth athletes with regards to these two constructs. Consequently, the purpose of this study was to investigate the relationship between parent-initiated motivational climate, coach-created motivational climate, and youth athletes' achievement goal orientation. A secondary purpose was to determine which construct, parent-initiated or coach-created motivational climate, had a greater influence on youth athletes' achievement goal orientation. The sample consisted of male and female basketball players $(N=98)$ between the ages of eight and twelve. Participants completed the Achievement Goal Scale for Youth Sports, the Motivational Climate Scale for Youth Sports, and the Parent-Initiated Motivational Climate Scale 2, and correlations were calculated for each of the scales. Results showed that when youth athletes perceived a mastery climate, they were more likely to report a task orientation. Conversely, when they perceived an ego climate, they were more likely to report an ego climate. Additionally, regression analyses revealed that perceptions of coach-created motivational climate were the more significant predictor of achievement goal orientation when compared to parent-initiated motivational climate. Future research in this area should attempt to further characterize the relationship between coaches, parents, and youth athletes with regards to motivational climate and achievement goal orientation, as well as investigate the impact of motivational climate interventions on the youth sport experience. 


\section{Acknowledgements}

First and foremost, I would like to thank my chair and advisor, Dr. Damien Clement, for all of the time and effort he has put into this project. Your guidance, from conceptualization all the way to the final manuscript, has been incredible, and I'm certain this project would not be finished if it wasn't for all of your help. More importantly, your investment in this project and your help along the way has been an invaluable part of my growth as a researcher, as a student, and as a future professional in our field. If I filled the rest of these pages with thank you's, I would not have said it enough.

I would also like to thank Dr. Jack Watson for serving on my committee and providing important feedback throughout the various stages of this project. Thank you as well for the incredible amount of help you provided in gaining access to the basketball leagues that I worked with during this study, and for your insight into the potential pitfalls that come with working with a bunch of eight to twelve year olds!

I am also grateful to Dr. Ed Jacobs for serving on my committee. I am thankful for the feedback you provided throughout this process, and for the time you have made in order to be a part of this project.

I would like to extend a thank you to Dr. Vanessa Shannon for her help early in the development of this research project. Your research wisdom helped give me a better understanding of how research comes together from start to finish. I would also like to extend my gratitude to Dr. Sam Zizzi for his statistical prowess and his help when the regressions started to get the best of me.

I would like to thank Julian Jacquez of the North Basketball League and Shelly Martin of the Westside Basketball League for all of the extra time and effort they put into helping me track down coaches and players, and for their flexibility in allowing me to enter into their sometimeschaotic world so graciously. Additionally, I would like to thank all of the coaches who allowed me to take time out of practice or interrupt pre- and post-game meetings in order to have a few minutes with their athletes. My gratitude also goes out to all of the parents who were willing to shuffle their busy schedules around in order to get their children to the gym early or who were willing to stay late so that I could speak with their kids. Without the generosity of you all, I would not have had a fighting chance in getting this project off the ground. Of course, I would also like to thank all of my participants, who were patient and diligent throughout the process, and perpetually blew me away with their maturity, not to mention their basketball ability! You all were the beginning and the end of this project, and I cannot say thank you enough.

I would like to thank everyone in the Sport and Exercise Psychology Program at West Virginia University. I am thankful not only to call you all colleagues, but also friends. Thank you for everything you have given me.

Finally, I would like to thank my beautiful, amazing family. Pop, Momma and Bebo, words simply do not do justice to what you guys mean to me. Without your love and unconditional support I would not be half the man I am today. Thank you. 


\section{TABLE OF CONTENTS}

Page

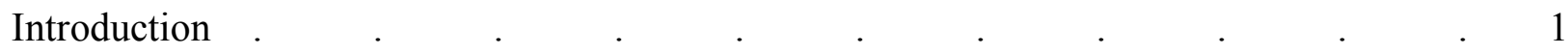

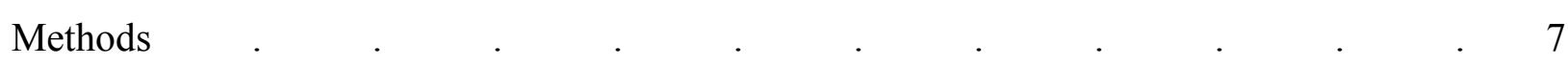

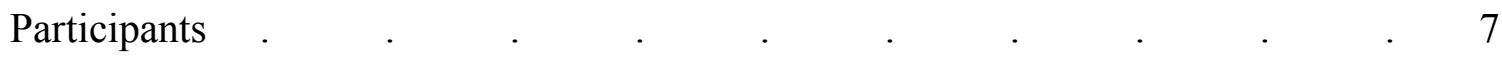

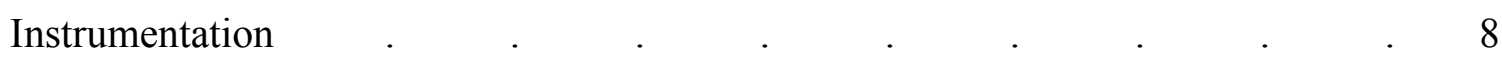

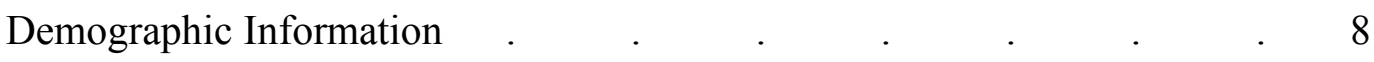

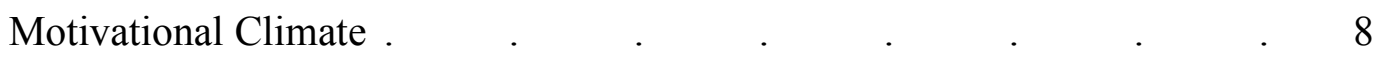

$\begin{array}{llllllllll}\text { Parent-Initiated Motivational Climate } & \text {. } & \text {. } & & & & & & & \end{array}$

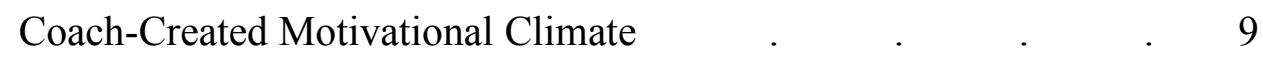

Achievement Goal Orientation $\quad . \quad$. $\quad . \quad$. $\quad . \quad$. 10

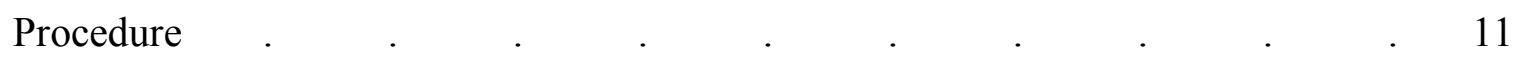

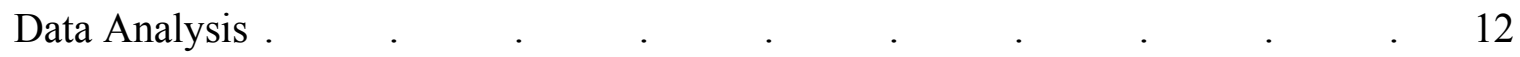

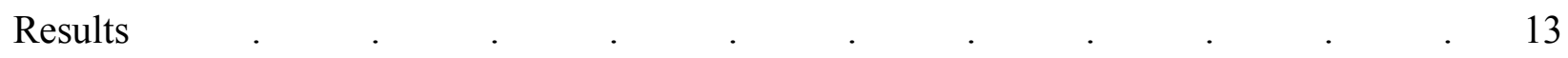

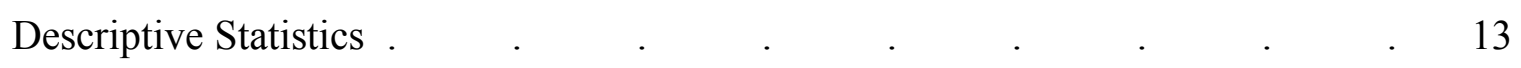

Parent-Initiated Motivational Climate and Achievement Goal Orientation . 13

Coach-Created Motivational Climate and Achievement Goal Orientation . 14

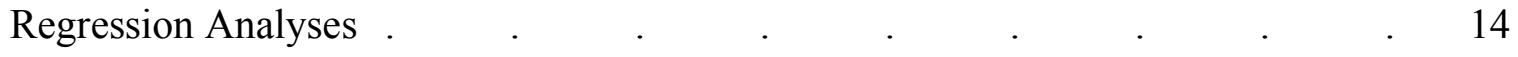

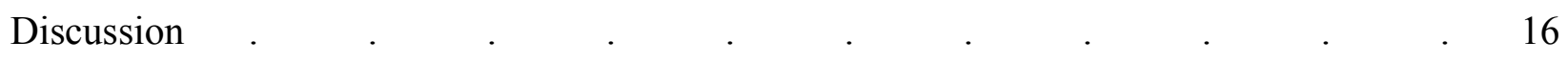

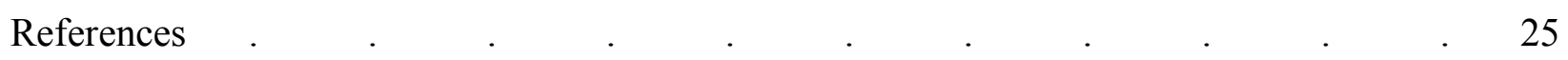

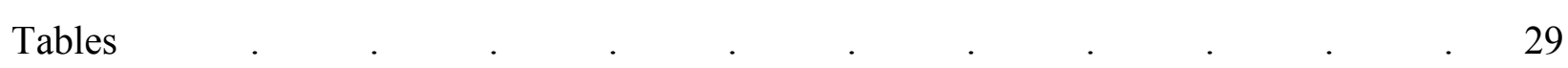

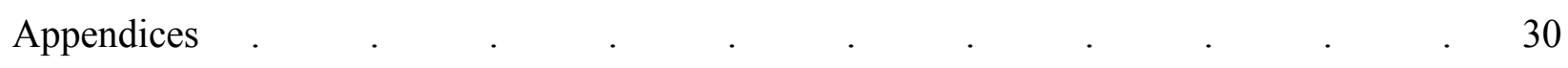

Appendix A - Demographic Questionnaire . $\quad . \quad$. $\quad . \quad$. $\quad 30$ 
Appendix B - Parent-Initiated Motivational Climate Scale - 2 . $\quad$. $\quad$. 32

Appendix C - Motivational Climate Scale for Youth Sports . $\quad$. $\quad$. $\quad$. 37

Appendix D - Achievement Goal Scale for Youth Sports . $\quad$. $\quad$. $\quad 39$

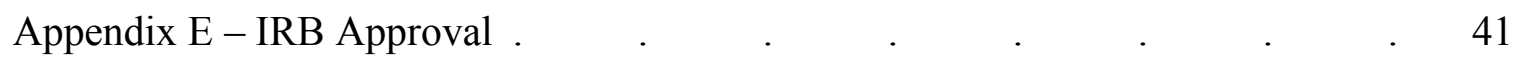

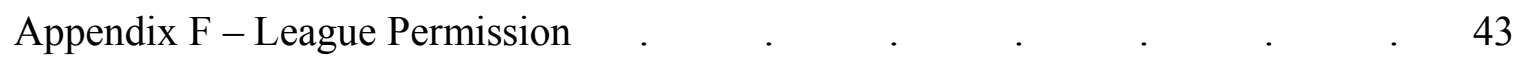

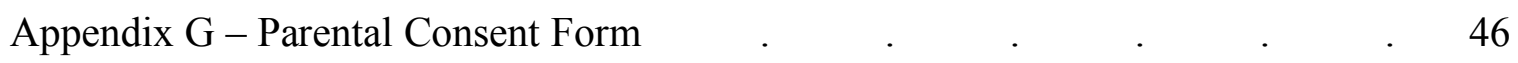

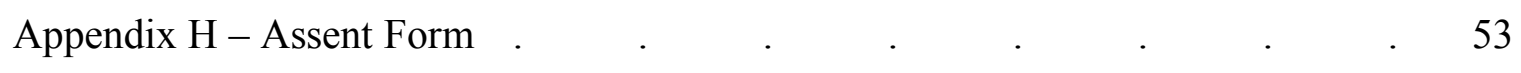

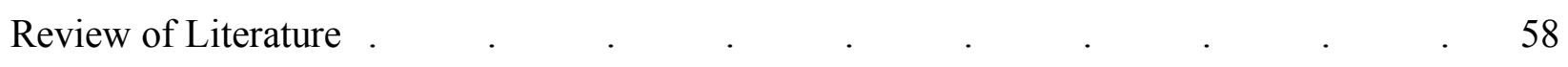




\section{LIST OF TABLES}

Page

Table 1 - Subscale Means and Cronbach's Alphas . _ . $\quad$. $\quad$. $\quad . \quad 29$

Table 2 - Correlations between Youth Athletes' Achievement Goal Orientation . 29 and Motivational Climate Subscales 
Perceptions of Parent-Initiated and Coach-Created Motivational Climate and their Influence on Youth Athlete Achievement Goal Orientation

It has been known for several decades that sports can have a profound impact on youth athletes' development of important physical, emotional, and social skills (Danish, Petitpas, \& Hale, 1990; Larson, 2000; Taliaferro, Rienzo, \& Donovan, 2010). Researchers looking at the impact of sports on youth athletes have focused on the psychosocial impact of sport participation, finding that experience in youth sports has the possibility of positively influencing youth athletes in a number of ways, including, but not limited to, increasing self-esteem, motivation, and feelings of competence (Roberts \& Treasure, 1992; Smith \& Smoll, 1990; Vazou, Ntoumanis, \& Duda, 2006). Conversely, there is also the potential for negative experiences, such as increased levels of competitive trait anxiety in addition to many athletes discontinuing their sport involvement due to the excessive pressure placed on them (Gould, 1987; Smith, Smoll, \& Cumming, 2007). With both positive and negative outcomes potentially emerging from the youth sporting experience, it is important to fully characterize the factors and individuals who may influence these outcomes.

Researchers looking to understand the varied influences on the youth sport experience have often looked at the role that parents and coaches play in the sport environment. Brustad's (1992) review of parent and coach socialization literature established a firm connection between parents and coaches and their influence on youth athletes in various aspects of sport, including feelings of competence and their beliefs about success. Research by Horn and Hasbrook (1986) and Fuligni and Eccles (1993) has shed light on developmental changes that occur as children move into adolescence. These findings suggest that during the transition from childhood to adolescence, athletes may begin to place more emphasis on input from coaches, peers, and social 
comparison as opposed to input from parents. Based on this relationship, researchers have looked closely at the influence that significant socializing agents (i.e., parents and coaches) have on the sport environment for adolescents (Bergin \& Habusta, 2004; Givvin, 2001; Vazou et al., 2006). Conversely, less research has looked at the impact that parents and coaches have on the sporting environment at a youth level. Researchers who are looking to assess the influence of coaches and parents in sport have used a number of ways to conceptualize mechanisms through which athletes are influenced. One of the aspects of the sport environment that has received an increasing amount of attention is motivational climate (Ames, 1992; Smith, Smoll, \& Cumming, 2009; Williams, 1998).

Motivational climate can be described as the situational factors that significant others (e.g., parents, teachers, coaches, etc.) create that influence an athlete's beliefs about success (Ames, 1992; Smith et al., 2009). In an effort to better understand the factors that might affect motivational climate, researchers have studied the influence of both coaches and parents on motivational climate (Smoll, Smith, \& Cumming, 2007; White, 1998). Results have shown that parents' and coaches' beliefs about success can influence athletes' perceptions of motivational climate. This is important because motivational climate is closely associated with another theory, achievement goal orientation, which can have far reaching implications on an athlete's sport experience.

Originally defined by Nicholls (1984), achievement goal theory proposes that individuals approach success in two ways. An individual who perceives success as being self-referenced, and defines success in terms of task mastery and effort is said to be "task oriented." On the other hand, an individual who defines success compared to opponents or a normative reference group, and who defines success as displaying superiority or winning is said to be "ego oriented." It is 
important to note that these two constructs are orthogonal, meaning that an athlete could potentially be both task- and ego-oriented (Nicholls, 1984).

Based on the literature examining the relationship between achievement goal orientation and motivational climate, the situational factors (e.g., behaviors that reward hard work, punishment when an athlete makes a mistake, etc.) that are associated with mastery and performance climates may predispose an individual to adopt either a task or ego orientation (Smoll et al., 2007). Previous research has shown that a strong relationship exists between mastery climates and task orientation, and performance climates and ego orientation when looking at both coach-created (Smith et al., 2007; Smith et al., 2009) and parent-initiated motivational climates (Waldron \& Krane, 2005; White, 1996). It is important to note, however, that the perceptions of parent and coach behaviors and thoughts about success tend to be a more accurate predictor of athlete goal orientation when compared to those parents' and coaches' selfreported behaviors and thoughts about success (Givvin, 2001). Thus, athletes who perceive an environment where hard work is rewarded and the focus is on improving their skills may be more likely to adopt a task orientation, whereas athletes who perceive an emphasis on winning at all costs and comparing their performance against others may be more likely to adopt an ego orientation.

Achievement goal orientation and motivational climate have shown to be significant areas of interest in youth sports based on the potential implications of having a high task and/or ego orientation. Research into the influence of goal orientation on youth and adolescent athletes has found that athletes who are primarily task-oriented are more likely to display high effort, have increased motivation and self-esteem, high levels of perceived competence, and decreased levels of anxiety when compared to athletes who are primarily ego-oriented (Black \& Weiss, 
1992; Smith et al., 2007; Vazou et al., 2006). In addition, task-oriented athletes have also reported lower levels of attrition in sports (Barnett, Smoll, \& Smith, 1992; Smoll et al., 2007). This is contrasted with athletes who are primarily ego-oriented, who have reported increased levels of anxiety, high attrition rates, and lower levels of self-esteem when compared to those athletes who score high in task-orientation (Barnett et al., 1992; Black \& Weiss, 1992; Smith et al., 2007). It is important to note that despite the orthogonal nature of achievement goal orientation, few studies have chosen to look at athletes who are either high in both ego- and taskorientation, or those athletes who score low for both constructs (Williams, 1998). This makes it difficult to draw conclusions about athletes who fall into these goal orientation profiles. Based on the impact that achievement goal orientation can have on psychosocial outcomes, researchers have begun to examine ways to positively impact motivational climate, and thus influence athletes' achievement goal orientations.

Research looking specifically at coach and parental influence on motivational climate in adolescent populations has provided strong support for the connection between perceptions of parents' and coaches' motivational climate, and athletes' achievement goal orientation (Givvin, 2001; Smith et al., 2009; Smoll et al., 2007; White, 1998). Using a coaching behavior intervention, Smoll and colleagues (2007) successfully altered coaching behaviors in order to increase athletes' perceptions of a mastery climate, which in turn increased their self-reported task orientation. These results indicated that coaches can play a role in influencing youth achievement goal orientation and more importantly, that interventions can be effective in impacting athletes' perceptions of motivational climate as well as their achievement goal orientation. While there have been no studies looking at parental behavior interventions, 
research looking at the relationship between parent-initiated motivational climate and athlete achievement goal orientation has yielded similar results (White, 1998).

More specifically, White (1998) investigated the relationship between perceptions of parent-initiated motivational climate and achievement goal orientation in adolescent athletes, finding similar results as studies investigating coach-created motivational climate. That is, athletes who were high in self-reported ego-orientation were more likely to perceive a parentinitiated motivational climate where emphasis was placed on success with little effort and there was an increase in worry when athletes made mistakes. Contrasting this with athletes who were high in self-reported task-orientation, there was a perception that parents endorsed learning and enjoyment. These findings help establish a connection between athletes' perceptions of their parents behaviors and beliefs about success and their own achievement goal orientation. Further investigation into parents' role in adolescent sports has reported similar findings (Givvin, 2001; Waldron \& Krane, 2005).

However, when comparing the influence of both coaches and parents on achievement goal orientation, continued research has suggested that adolescents' achievement goal orientation is more consistent with coach-created motivational climate than parent-initiated motivational climate. Givvin (2001) reported that although perceptions of parent-initiated motivational climate were related to adolescents' achievement goal orientation, coach-created motivational climate was a stronger predictor of achievement goal orientation. Furthermore, Waldron and Krane (2005) found that changes in task orientation over the course of a season were attributed more to coach-created motivational climate than to parent-initiated motivational climate. This may be due to the developmental changes that take place during the transition from childhood to adolescence. During this period, the relationship between parents and children is often 
characterized by a decrease in closeness and an increase in conflict (Holmbeck, 1996). It is suggested that these changes take place as the adolescent begins developing a sense of independence and autonomy (Holmbeck, 1996). The way parents interact with their children also changes during this time, with research finding that during adolescence parental responsiveness and involvement in school and sports may decrease, while their values towards their child's achievements remains the same (Paulson \& Sputa, 1996). In other words, during the transition from childhood to adolescence, the parent-child relationship begins to shift, with the parents taking on a less central role in their child's life. This could potentially result in decreased influence of parent-initiated motivational climate on an adolescent's goal orientation when compared to youth athletes, making it important to investigate the degree to which parents play a role in youth athletes' beliefs about success.

Despite the results of studies done with adolescent populations examining coach and parent influence, there has been no research investigating the impact of parent-initiated motivational climate at the youth sport level. Furthermore, there has been no comparison of the degree to which coaches and parents play a role in shaping youth athletes' achievement goal orientation. With a lack of research into the influence of parents on goal orientation in youth sports and studies that suggest coaches are a more significant indicator of achievement goal orientation at an adolescent level, it is necessary to investigate the influence of parents as well as coaches on youth athletes' achievement goal orientations. As a result, the main research questions for the proposed study were: (a) is there a relationship between athletes' perceptions of parent-initiated motivational climate and self-reported achievement goal orientation of youth athletes?; (b) is there a relationship between athletes' perceptions of coach-created motivational climate and self-reported achievement goal orientation of youth athletes?; (c) which construct, 
parent-initiated or coach-created motivational climate, accounts for more of the variance in youth athletes' achievement goal orientation?

It was hypothesized that the perceptions of a parent-initiated mastery climate would be positively correlated with self-reported task orientation and negatively correlated with ego orientation. Likewise, it was predicted that perceptions of a parent-initiated performance climate (i.e., success without effort climate and worry conducive climate) would be negatively correlated with self-reported task orientation and positively correlated with self-reported ego orientation (White, Kavussanu, \& Guest, 1998). The author also hypothesized that the perceptions of a coach-created mastery climate would be positively correlated with self-reported task orientation, and negatively correlated with ego orientation. It was also predicted that perceptions of a coachcreated ego climate would be positively correlated with self-reported ego orientation and negatively correlated with task orientation for youth athletes (Papaioannou, Marsh, \& Theodorakis, 2004). Finally, it was hypothesized that the perceptions of parent-initiated motivational climate would account for more variance in athletes' achievement goal orientation than coach-created motivational climate. This is based on previous developmental research that illuminates the shifting of parents' roles during the transition from childhood to adolescence (Holmbeck, 1996; Paulson \& Sputa, 1996). Extrapolating the developmental hypothesis out further, it was predicted that younger athletes (ages 8-10) would be more influenced by parentinitiated motivational climate than those athletes who were older (ages 11-12).

\section{Participants}

\section{Methods}

The initially recruited sample for this study consisted of athletes $(N=107)$ from two youth basketball leagues in a Mid-Atlantic state. Participants were recruited from different teams $(n=21)$ across both leagues. The decision to recruit athletes who played the same sport 
was made in order to help control for the influence of sport on the relationship between motivational climate and goal orientation (Smith et al., 2009). Nine athletes failed to complete the second data point, thus accounting for the decreased number of participants in the final sample (males: $n=89 ; M=10.06$ years, $S D=1.10$; females: $n=9 ; M=10.56, S D=1.236$ ). Participants reported playing basketball for an average of 4.25 years $(S D=1.86)$, in addition to playing for their current coach for an average of 1.91 years $(S D=1.41)$. With regard to the number of parents at home, $79 \%(n=77)$ of the participants had two parents in their household, with $16 \%(n=17)$ reporting a single parent household, and $5 \%(n=5)$ of the participants not responding to this item. When asked which parent was most influential on their sport participation, $45 \%(n=44)$ indicated their father, $22 \%(n=22)$ their mother, and 28\% $(n=27)$ reported both parents.

\section{Instrumentation}

Demographic Information. Demographic information collected included age, year in school, number of years playing basketball, and the number of years the athlete has played for their current coach. Information about the number of parents in the household and the athlete's perception of their most significant sports parent was also obtained (see Appendix A).

Motivational Climate. Motivational climate was assessed using two different questionnaires in order to accurately characterize both parent-initiated motivational climate and coach-created motivational climate.

Parent-Initiated Motivational Climate. Parent-initiated motivational climate was measured using the Parent-Initiated Motivational Climate Questionnaire (PIMCQ-2; White, Duda, \& Hart, 1992; White, 1996; see Appendix B). The PIMCQ-2 is a 36-item questionnaire that assesses athletes' perceptions of the motivational climate initiated by their fathers and 
mothers. The questionnaire contains three subscales: Learning/Enjoyment Climate, Worry Conducive Climate, and Success Without Effort Climate. The PIMCQ-2 is divided into two parts, with 18 items, each addressing father-initiated motivational climate and 18 items assessing mother-initiated motivational climate. Participants respond using a 5-point Likert scale ranging from 1 (strongly disagree) to 5 (strongly agree). The questionnaire is scored by calculating the mean score for each subscale, with mean scores ranging from one to five, and comparing them to the other subscale means to determine whether an individual perceives a task or ego climate.

The subscales of the PIMCQ-2 have high reliability when used with a youth sample: Learning/Enjoyment (0.91), Worry Conducive Climate (0.89), Success Without Effort Climate (0.87), (White, 1996). Assessment of criterion-validity found that the learning/enjoyment climate subscale was correlated with a task-orientation $(r=0.41)$ and the success without effort climate subscale was correlated with an ego-orientation $(r=0.30$; White et al., 1992). It is important to note that the strength of the criterion-validity is moderate. Despite this, the PIMCQ-2 was utilized due to the lack of instruments developed to measure perceptions of parent-initiated motivational climate. No other validity information was provided for the PIMCQ-2.

Coach-Created Motivational Climate. Coach-created motivational climate was measured using the Motivational Climate Scale for Youth Sports (MCSYS; Smith, Cumming, \& Smoll, 2008; see Appendix C). The MCSYS is a twelve-item scale that assesses youth athletes' perceptions of coach-created motivational climate. The MCSYS contains two, six-item subscales measuring mastery and ego climate and has been used to assess perceptions of coachcreated motivational climate in youth populations (Smith et al., 2007; Smith et al., 2009). The subscales are answered using a 5-point Likert scale ranging from 1 (not at all true) to 5 (very 
true). The questionnaire is scored by calculating the mean score for each subscale, with mean scores ranging from one to five. Cronbach's alphas were moderate to high, ranging from 0.78 0.84 for the mastery subscale and $0.74-0.75$ for the ego subscale (Smith et al., 2008). Testretest reliability was measured using a one-week interval between tests; the reliability for the mastery and ego subscales were 0.84 and 0.76 respectively (Smith et al., 2008). Discriminant validity was established by investigating the relationship between the two subscales. The correlation coefficient between the mastery and ego subscales was -0.38 (Smith et al., 2008).

Achievement Goal Orientation. Achievement goal orientation was measured using the Achievement Goal Scale for Youth Sports (AGSYS; Cumming, Smith, Smoll, Standage, \& Grossbard, 2008; see Appendix D). The AGSYS contains 12 items divided into two, six-item subscales and has been used to measure 8self-reported achievement goal orientation in youth athletes (Smith et al., 2007; Smith et al., 2009). The subscales measure mastery and ego orientation, and are answered using a 5-point Likert scale ranging from 1 (not true at all) to 5 (very true). The AGSYS is scored by calculating the mean scores of each subscale, with mean scores ranging from one to five. (Cumming et al., 2008).

The Cronbach's alpha coefficient for the mastery subscale was 0.78 , and the ego subscale had a coefficient of 0.88 (Cumming et al., 2008). Test-retest reliability for the mastery and ego subscales were 0.92 and 0.95 respectively, with the scales administered a week apart. In order to determine construct validity, the AGSYS subscales were compared to the Perception of Success questionnaire, with the mastery subscale having a correlation coefficient of 0.49 and the ego subscale having a coefficient of 0.68 (Cumming et al., 2008). Discriminant validity was established with the subscales having a correlation coefficient of 0.01 , which is congruent with previous achievement goal orientation research (Nicholls, 1984). 


\section{Procedure}

Prior to participant recruitment, directors of two local youth basketball organizations were contacted and asked if their leagues were interested in helping with a research study investigating the relationship between parents' and coaches' beliefs about success and youth athletes' beliefs about success (see Appendix F). Approval was acquired from the Institutional Review Board prior to proceeding with the recruitment (see Appendix E). Participants were recruited by contacting the coaches in the league prior to visiting the team's practice, at which point athletes were asked if they would be interested in completing a few brief questionnaires as part of a graduate student research project.

There were two separate data collection points during the study. The first data collection occurred either before or after a regular season practice or game. Data collection began roughly four weeks into the regular season. Participants were informed of the purpose of the study, as well as the potential benefits and risks associated with participating in the study. Parental consent (see Appendix G) and youth athlete assent (see Appendix H) were obtained prior to distributing the questionnaire packet. During the first data collection point, participants completed the demographic questionnaire, and the PIMCQ-2 in order to assess their perceptions of parent-initiated motivational climate.

The second data point occurred during the final weekend of league games for both leagues, with the athletes completing both the MCSYS and AGSYS in order to assess their perceptions of coach-created motivational climate as well as their own achievement goal orientation. By allowing the athletes to practice and play for the season prior to administering the MCSYS, the athletes were provided with enough time to become acclimated to the coaches' behaviors, providing them with a developed sense of the coach-created motivational climate. By 
waiting to administer the AGSYS, it allowed time for any influence that coach-created motivational climate might have on youth athletes' achievement goal orientation to take place.

\section{Data Analysis}

The data was entered and analyzed using SPSS v.19. Descriptive statistics, including means and standard deviations were calculated for the demographic information, as well as the subscales for each questionnaire. Cronbach's alphas were also calculated for each of the scales during data analysis. Correlational analyses were used to investigate both hypotheses one and two. More specifically, pearson-product correlation coefficients were calculated between the MCSYS to the AGSYS to examine the relationship between coach-created motivational climate and achievement goal orientation. Pearson-product correlation coefficients were also calculated between the subscales of the PIMCQ-2 and the AGSYS to investigate the relationship between parent-initiated motivational climate and achievement goal orientation. A regression analysis was used to determine the amount of variance in achievement goal orientation that is explained by parent-initiated and coach-created motivational climate, as well as age and the number of years playing for their coach. Additionally, exploratory analyses were done in order to examine the difference in variance explained by parent-initiated motivational climate across two separate age groups. Based on the underlying developmental explanation for the current study's hypotheses, it was important, despite the lack of sample size, to try and understand the impact that age might play on the relationship between youth athletes, their coaches, and their parents. More specifically, it would make sense that as children get older, moving from late childhood to pre-adolescence, that their relationship to both parents and coaches might change. In order to assess this, the data was split by age, with the younger group consisting of eight to ten year olds, with the older group having athletes from age eleven to twelve. To assess the difference in 
variance across different age groups, two additional regression analyses were run. Each model contained parent-initiated motivational climate, coach-created motivational climate, and the number of years playing for their coach. The level of significance for this study was set at $p<$ 0.05 .

\section{Results}

\section{Descriptive Statistics}

The sample of youth basketball athletes in the current study reported being higher in task orientation $(M=4.58, S D=.42)$ than ego orientation $(M=2.46, S D=1.04)$. Athletes' perceptions of coach created motivational climate suggested that coaches created a mastery climate $(M=4.46, S D=.59)$ as opposed to an ego climate $(M=1.84, S D=.66)$. Similarly, athletes reported that parents created a climate focused primarily on learning/enjoyment $(M=$ $4.40, S D=.43)$ and to a lesser extent a success without effort $(M=2.00, S D=.80)$ and worry conducive climates $(M=2.10, S D=.85)$. For the means, standard deviations, and Cronbach's alphas for each subscale, please refer to Table 1. All of the subscales, except for athletes' task orientation, mother's learning/enjoyment and success without effort climates, and coach-created ego climate, displayed acceptable internal consistency ( $\alpha>.70$; Cortina, 1993).

\section{Parent-Initiated Motivational Climate and Achievement Goal Orientation}

Overall, parent-initiated motivational climate was weakly to moderately correlated with youth athletes' self-reported achievement goal orientation (see Table 2). More specifically, father's learning/enjoyment climate was moderately correlated with youth athletes' self-reported task orientation $(r(83)=.34, p<.01)$, while mother's learning/enjoyment climate was weakly correlated with self-reported task orientation $(r(87)=.25, p<.05)$. There were no significant correlations between parents' learning/enjoyment climate and ego orientation. 
Father's success without effort climate was moderately correlated with self-reported ego orientation $(r(88)=.35, p<.01)$, while mother's success without effort climate was weakly correlated with youth athletes' ego orientation $(r(89)=.26, p<.05)$. There was a weak, negative correlation between father's worry conducive climate and self-reported task orientation $(r(86)=$ $.24, p<.05)$, as well as mother's worry conducive climate and athletes' task orientation $(r(91)=$ $-.26, p<.05)$. Both parents' success without effort climates were not significantly correlated with self-reported task orientation. Similarly, neither father nor mother created worry conducive climate was significantly related to self-reported ego-orientation.

\section{Coach-Created Motivational Climate and Achievement Goal Orientation}

Youth athletes' perceptions of coach-created motivational climate were weakly to moderately correlated with self-reported achievement goal orientation. Coach-created mastery climate was moderately correlated with youth athletes' self-reported task orientation $(r(86)=.65$, $p<.01$, while perceptions of a mastery climate were not significantly related to ego orientation. Conversely, coach-created ego climate was weakly correlated with youth athletes' ego orientation $(r(88)=.30, p<.01)$, and moderately, negatively, correlated with youth athletes' task orientation $(r(89)=-.39, p<.01)$.

\section{Regression Analyses}

The results of the multiple regression analyses revealed that for self-reported task orientation, five predictors (i.e., years played for coach, age, both mother's and father's learning/enjoyment climate subscale, and coach-created mastery climate) explained $53 \%$ of the variance $\left(R^{2}=.53, F(5,68)=15.31, p<.01\right)$. The only significant predictor in the model was the athletes' perception of coach-created mastery climate $(ß=.735, p<.01)$. For athletes' selfreported ego orientation, the regression analysis included both mother's and father's success 
without effort and worry conducive subscales, as well as coach-created ego climate, age, and years played for their coach. Results showed that the seven predictors explained $19 \%$ of variance in youth athletes' ego orientation $\left(R^{2}=.19, F(7,73)=2.39, p<.05\right)$. The only significant predictor in the model was the participants' perception of coach-created ego climate $(ß=.293, p<.05)$.

In order to examine the difference across age in the variance of achievement goal orientation explained by parents' and coaches' motivational climate, the sample was split into two groups. The first group included participants between the ages of eight and ten $(n=61)$, and the second group included participants between the ages of eleven and twelve $(n=37)$. Examining the difference in variance explained in task orientation by parent-initiated mastery climates across age, the first regression model included group one. The model was significant, with the four predictors (i.e., Mother and Father learning/enjoyment climate, coach-created mastery climate, and years played for current coach) explaining $51 \%$ of the variance in task orientation $\left(R^{2}=.51, F(4,42)=10.82, p<.01\right)$. There was only one significant predictor of task orientation, which was coach-created mastery climate $(\beta=.715, p<.01)$. The second model included the same predictors, but included the second group, with participants between eleven and twelve years old. The overall model was significant, explaining $70 \%$ of the variance in task orientation $\left(R^{2}=.70, F(4,22)=12.85, p<.01\right)$. There were two significant predictors in the model, coach-created mastery climate $(ß=.933, p<.01)$ and mother's learning/enjoyment climate $(\beta=-.371, p<.05)$. Neither of the regression models looking at the change in parentinitiated motivational climate influence across age were significant. 


\section{Discussion}

Previous research into the influence of parents and coaches on athletes' achievement goal orientation has primarily investigated the relationship in adolescent populations (Givvin, 2001; Waldron \& Krane, 2005; White, 1998). When researchers have looked at the interaction of motivational climate and achievement goal orientation at the youth level, they have traditionally chosen to focus on the influence of coach-created motivational climate without addressing the role of parents in shaping youth athletes' goal orientations (Smith et al., 2009; Smoll et al., 2007). The current study examined the relationship between parent-initiated and coach-created motivational climate, and youth athletes' achievement goal orientation. In general, participants were somewhat more likely to define success in a way that was congruent with the motivational climate created by both parents and coaches. When the athletes perceived a parent or coach mastery climate, they were more likely to report being task oriented. Similarly, when the participants perceived an ego climate, they were more likely to report being ego oriented. While perceptions of parent-initiated and coach-created motivational climate were significantly related to the participants' achievement goal orientation, results of the multiple regression analysis revealed that perceptions of coaches' motivational climate may have a more significant influence on youth athlete achievement goal orientation than parents' motivational climate.

The current study's first hypothesis was partially supported with regard to the relationship between perceptions of parent-initiated motivational climate and youth athlete achievement goal orientation. Athletes who perceived a climate where their parents rewarded learning/enjoyment were more likely to report being high in task orientation. Similarly, athletes who perceived a climate where success without effort was valued were more likely to report higher ego orientation scores, and athletes who believed their parents made them worry were less 
likely to be high in task orientation. Previous investigation into parent-initiated motivational climate at the adolescent age fits a similar pattern, with White (1998) and White, Kavussanu, and Guest (1998) finding that athletes who perceived a learning/enjoyment climate or reported low perceived worry conducive or success without effort climates reported a high task orientation.

It is likely that the current hypothesis may have oversimplified the relationship between motivational climate and achievement goal orientation when it was predicted that perceptions of motivational climate would not only be positively correlated with their corresponding goal orientation, but would also be negatively correlated with the other goal orientation (i.e., mastery climate being positively correlated with task orientation and being negatively correlated with ego orientation). There are a number of possible explanations for these results. One potential explanation is that without a large sample size, there may not have been enough statistical power to identify the relationship between the motivational climate subscales and self-reported achievement goal orientation. Another possible explanation may lie in the orthogonality of achievement goal orientation, which was best represented by White's (1998) four-group model of achievement goal orientation (i.e., high task/high ego, high task/low ego, low task/high ego, low task/low ego). It is possible that certain aspects of an ego climate (e.g., punishment for mistakes, focusing on outcome) may contradict a mastery climate, while others, such as rewarding athletes for succeeding without effort, may not impact task orientation as greatly (Smith et al., 2009). Since the PIMCQ-2 has two subscales to assess perceptions of ego climate, it may also be possible that each subscale taps different aspects of an ego climate, which may help explain the difference between the two ego subscales and their relationship to achievement goal orientation. 
The second hypothesis was partially supported by the results of the current study, with athletes who perceived a coach-created mastery climate more likely to report having a task orientation, and athletes who perceived a coach-created ego climate were more likely to report having an ego orientation, while they were less likely to identify themselves as task oriented. These results are consistent with previous literature investigating the relationship between coachcreated motivational climate and youth athletes' achievement goal orientation (Smith et al., 2008; Smith et al., 2009). However, there was no significant relationship found between coachcreated mastery climate and athlete ego orientation, which contradicts previous research related to the influence of coach-created motivational climate (Papaioannou et al., 2004; Smith et al., 2008). Similar to the findings on parent-initiated motivational climate, these results highlight the fact that a coach may promote hard work, effort, and skill mastery, while at the same time encouraging youth athletes to strive to beat others in competition and to win.

Results from the first two regression analyses, which examined the sample as a whole, revealed that for both task and ego orientation, coach-created motivational climate were the only significant predictor of an athletes' goal orientation, thus refuting the current study's third hypothesis. These results were consistent with literature regarding the relationship between adolescents' goal orientation and both parents' and coaches' motivational climate, which has shown the coach to be a greater influence on youth athletes' achievement goal orientation when compared to parents (Waldron \& Krane, 2005).

However these results contradicted the developmental hypothesis put forth in the current study. It was posited that youth athletes, who had not yet begun the transition into adolescence and the associated drive for independence and autonomy, would be influenced to a greater degree by their parents' beliefs about success than their adolescent counterparts (Holmbeck, 
1996). One possible explanation for these findings could be that across both childhood and adolescence, the coach may be seen as having a higher amount of sport-specific knowledge when compared to parents in a sport setting. This would help explain the stability of the influence that coaches have on both children and adolescents, even as the relationship between parents and their children begins to shift. No research has been done to highlight this aspect of the coachathlete relationship, and it may be useful for future studies to investigate the underlying reasons for these results. Additionally, it is important to note that in the current study, athletes who were being coached by their parents, as is often the case in youth sports, were not used in the data analysis, which may have also attributed to the fact that coaches were a more significant influence on achievement goal orientation than parents.

To further investigate the relationship between age and the degree of influence that parents and coaches have on youth athletes' achievement goal orientation, the sample was split by age, and exploratory regression analyses were run in an attempt to identify any possible change in the degree of variance explained in achievement goal orientation across the two groups. Results for the younger group showed that task orientation was best explained by coachcreated mastery climate, and that the strongest predictor for an ego orientation was the athletes' perception of their fathers' valuing success without effort. These results may be explained by the fact that coaches are responsible for teaching sport skills, providing them with an opportunity to reinforce task related behaviors (i.e., improving one's form, increasing effort). This explanation also lacks research to support its validity, and future studies looking to tease apart the factors related to parents-coach-athlete relationship may want to look at this more closely. Additionally, participants in the current study identified their father as their most significant sport parent, which is consistent with the fact that fathers were the strongest predictor of athletes' ego 
orientation. Another possible explanation is that there are mediating variables that influence the relationship between the age of youth athletes and the degree to which they are influenced by parent-initiated and coach-created motivational climate that were not accounted for in the current study.

The older age group showed a somewhat different trend when compared to the younger group. Variance in task orientation was best explained by coach-created mastery climate, but mother's learning/enjoyment climate also had a significant negative beta weight, suggesting that the perception that mothers encouraged a learning/enjoyment climate had a negative impact on task orientation. This result conflicts with most of the published research, which suggests that a mastery climate should be positively correlated with task orientation (Givvin, 2001; Waldron \& Krane, 2005). This unusual finding may be explained by the limited sample size used for the regression analysis.

Both coach-created ego climate and fathers who created a worry conducive climate best predicted ego orientation in the older group. Looking at the changes across the two groups in the influence that parents and coaches have on youth athletes' achievement goal orientation, the trends do not match the developmental hypothesis that younger athletes would have a greater amount of variance in goal orientation explained by parent-initiated motivational climate when compared to the older group. This reflects the basic trend outlined in the first set of regression analyses, which showed the coach to be the more influential figure in the youth sport setting.

When interpreting these results, it is necessary to be aware of a number of limitations in the current study that might also be improved upon in future research. First, based on the availability of youth basketball athletes during the study's duration, there was insufficient sample size, and thus insufficient power to properly run the regression analyses. While the regression 
analyses provided some useful results, it is difficult to assess the accuracy of these results or draw any significant conclusions from the data based on the lack of power for the regression analyses. The lack of participants may also be responsible for the low internal consistency values that were calculated for some of the subscales (e.g., athlete task orientation, mother's learning and enjoyment climate), which were lower than previously reported Cronbach's alphas.

Second, there were a couple of methodological issues related to the use of the PIMCQ-2 for the current study. The PIMCQ-2 reports weak-to-moderate criterion validity, making conclusions about parent-initiated motivational climate difficult when using the scale. Despite these concerns, the scale was chosen because of the lack of other instruments that have been created to assess the perceptions of parent-initiated motivational climate, and the creation of a new scale to accurately assess this construct was beyond the scope of the current project. The PIMCQ-2, while reliable in youth populations, proved to be above the reading level for some of the participants in the study, which created a situation where parents often wanted to help their child with the questionnaire (White, 1996). While parents were asked to not help their kids and instead asked to allow one of the investigators to provide reading assistance, based on the setting this was unfeasible. Thus, this had the potential to influence the participants' responses, resulting in skewed data regarding parent-initiated motivational climate.

Third, the settings during which data collection took place were varied and often resulted in inconsistent data collection procedures. Data collection took place before and after practices, as well as before and after games. It is likely that based on the situational context of data collection with a given team (e.g., team had just lost a close game, team was preparing for a playoff game, team had just had a difficult practice, etc.), athletes' responses may have been very different. This also resulted in varied data collection procedures, as some athletes were late to 
practice or left early from games, creating a non-standardized data collection environment. Based on this, and the lack of investigators on-site for data collection, it became exceedingly difficult to make sure that the participants filled out their questionnaires thoroughly and without the help of a parent, sibling, or coach, which also may have influenced the data.

Despite these limitations, the current study presents a number of implications for future research. First, the results point to the coach as the most influential figure when it comes to impacting the ways that an athlete defines success. This lends further support to the work done by Smith and colleagues, who have been working on creating effective coaching education workshops over the last three decades, and suggests that this is a critical area of study that deserves continued attention.

Second, while parent-initiated motivational climate was not the strongest predictor of athletes' achievement goal orientation, both mothers and fathers still remain an important part of the overall youth sport equation. Future research should attempt to fully characterize the relationship between parents and youth athletes with regard to motivational climate and achievement goal orientation, as well as any potential interactions between parent-initiated and coach-created motivational climate. Third, the differences found in the relationship between mother-initiated motivational climate and father-initiated motivational climate suggests that looking at each parent's role in the motivational climate-achievement goal orientation relationship is warranted. It is also consistent with the responses of the majority of participants, who reported their father to be their most influential sport parent.

Fourth, it is recommended that future research should develop an age-appropriate scale that can be used to assess youth athletes' perceptions of parent-initiated motivational climate, as the use of the PIMCQ-2 severely limited the validity of the current study. It may be more 
appropriate to create a shorter, more global instrument that would enable researchers to quickly assess general perceptions of parent-initiated motivational climate. Finally, future research may investigate the use of parent education workshops aimed at teaching the concepts of achievement goal orientation and motivational climate to both mothers and fathers, assessing the impact these workshops have on perceptions of parent-initiated motivational climate, as well as on youth athletes' achievement goal orientation.

The results of the current study provide useful insight into the youth sport experience, and the influential significant others who are involved in shaping youth athletes' beliefs about success. The results of the current study help provide continued support for the relationship between motivational climate and achievement goal orientation for both coaches and parents. This may serve as a reminder that parents' and coaches' behaviors, and more importantly, their kid/athletes' perception of their behaviors, may have a significant impact on how they define success in a sport setting. While the current study simply examined the relationship between parents, coaches, and youth athletes, other studies have investigated the impact of task orientation on certain outcome variables, showing athletes who are primarily task oriented are more likely to enjoy themselves, have an increased sense of competence, and have decreased levels anxiety when compared to athletes with a predominantly ego orientation (Black \& Weiss, 1992; Smith et al., 2007; Vazou et al., 2006). Based on these potential positive outcomes associated with a task orientation, it may be useful for practitioners, coaching educators, parents, and coaches to become familiar with how to promote a mastery climate and the benefits related to improving youth athletes' task orientation.

Motivational climate and achievement goal orientation are promising avenues through which adults can have a positive influence on the youth sport experience. Coaches and parents 
are in a unique position to have a significant impact on youth at a critical period in their development (Danish, Petitpas, \& Hale, 1990; Larson, 2000). Sport psychology professionals can help provide parents and coaches in a variety of sports with an understanding of what task orientation and a mastery climate look like in a specific sport. Furthermore, sport psychology consultants can also provide both parents and coaches with strategies on how to promote task orientation in their athletes, which in turn may improve a number of outcome variables in the youth sport environment. Finally, the current study provides an opportunity for future research to extend these findings in an effort to better understand the relationship between parents, coaches, and youth athletes. It also lends support to the continued development of coaching education workshops, as well as the development and implementation of parent education workshops also geared towards mastery climate and task orientation promotion. 


\section{References}

Ames, C. (1992). Classrooms: Goals, structures, and student motivation. Journal of Educational Psychology, 84(3), 261-271.

Barnett, N. P., Smoll, F. L., \& Smith, R. E. (1992). Effects of enhancing coach-athlete relationships on youth sport attrition. The Sport Psychologist, 6, 111-127.

Bergin, D. A., \& Habusta, S. F. (2004). Goal orientations of young male ice hockey players and their parents. The Journal of Genetic Psychology, 165(4), 383-397.

Black, S. J., \& Weiss, M. R. (1992). The relationship among perceived coaching behaviors, perceptions of ability, and motivation in competitive age-group swimmers. Journal of Sport \& Exercise Psychology, 14(3), 309-325.

Brustad, R. J. (1992). Integrating socialization influences into the study of children's motivation in sport. Journal of Sport \& Exercise Psychology, 14, 59-77.

Cortina, J. M. (1993). What is Coefficient Alpha? An Examination of Theory and Applications. Journal of Applied Psychology, 78(1), 98-104.

Cumming, S. P., Smith, R. E., Smoll, F. L., Standage, M., \& Grossbard, J. R. (2008). Development and validation of the achievement goal scale for youth sports. Psychology of Sport and Exercise, 9, 686-703.

Danish, S. J., Petitpas, A. J., \& Hale, B. D. (1990). Sport as a context for developing competence. In T. Gullotta, G. Adams \& R. Monteymar (Eds.), Developing social competency in adolescence (pp. 169-194). Newbury Park, CA: Sage. 
Fugligni, A. J., \& Eccles, J. S. (1993). Perceived Parent-Child Relationships and Early Adolescents' Orientation Towards Peers. Developmental Psychology, 29(4), 622-632.

Givvin, K. B. (2001). Goal orientations of adolescents, coaches, and parents: Is there a convergence of beliefs? The Journal of Early Adolescence, 21(2), 228-248.

Gould, D. (1987). Understanding attrition in children's sport. In D. Gould, \& M. R. Weiss (Eds.), Advances in pediatric sport sciences (pp. 61-85). Champaign, IL: Human Kinetics.

Holmbeck, G. N. (1996). Transitions Through Adolescence: Interpersonal Domains and Context J. A. Graber, J. Brooks-Gunn, \& A. C. Petersen, (Eds.) . Mahwah, NJ: Lawrence Erlbaum Associates.

Horn, T. S., \& Hasbrook, C. A. (1986). Psychological characteristics and the criteria children use for self-evaluation. Journal of Sport Psychology, 9, 208-211.

Larson, R. W. (2000). Toward a psychology of positive youth development. American Psychologist, 55(1), 170-183.

Nicholls, J. G. (1984). Achievement motivation: Conceptions of ability, subjective experience, task choice, and performance. Psychological Review, 91(3), 328-346.

Papaioannou, A., Marsh, H. W., Theodorakis, Y. (2004). A Multilevel Approach to Motivational Climate in Physical Education and Sport Settings: An Individual or a Group Level Construct? Journal of Sport \& Exercise Psychology, 26, 90-118. 
Paulson, S. E., \& Sputa, C. L. (1996). Patterns of parenting during adolescence: Perceptions of adolescents and parents. Adolescence, 31(122), 369-381.

Roberts, G. C., \& Treasure, D. C. (1992). Children in sport. Sport Science Review, 1(2), 46-64.

Smith, R. E., Cumming, S. P., \& Smoll, F. L. (2008). Development and validation of the motivational climate scale for youth sports. Journal of Applied Sport Psychology, 20, 116136.

Smith, R. E., \& Smoll, F. L. (1990). Self-esteem and children's reactions to youth sport coaching behaviors: A field study of self-enhancement processes. Developmental Psychology, 26(6), 987-993.

Smith, R. E., Smoll, F. L., \& Cumming, S. P. (2007). Effects of a motivational climate intervention for coaches on young athletes' sport performance anxiety. Journal of Sport \& Exercise Psychology, 29(39), 59.

Smith, R. E., Smoll, F. L., \& Cumming, S. P. (2009). Motivational climate and changes in young athletes' achievement goal orientations. Motivation and Emotion, 33, 173-183.

Smoll, F. L., Smith, R. E., \& Cumming, S. P. (2007). Effects of a motivational climate intervention for coaches on changes in young athletes' achievement goal orientations. Journal of Clinical Sport Psychology, 1, 23-46.

Taliaferro, L. A., Rienzo, B. A., Donovan, K. A. (2010). Relationships Between Youth Sport Participation and Selected Health Risk Behaviors From 1999 to 2007. Journal of School Health, 80(8), 399-410. 
Vazou, S., Ntoumanis, N., \& Duda, J. L. (2006). Predicting young athletes' motivational indices as a function of their perceptions of the coach- and peer-created climate. Psychology of Sport and Exercise, 7, 215-233.

Waldron, J. J., \& Krane, V. (2005). Motivational climate and goal orientation in adolescent female softball players. Journal of Sport Behavior, 28(4), 378.

White, S. A. (1996). Goal orientation and perceptions of the motivational climate initiated by parents. Pediatric Exercise Science, 8, 122-129.

White, S. A. (1998). Adolescent goal profiles, perceptions of the parent-initiated motivational climate, and competitive trait anxiety. The Sport Psychologist, (12), 16-28.

White, S. A., Duda, J. L., \& Hart, S. (1992). An exploratory examination of the parent-initiated motivational climate questionnaire. Perceptual and Motor Skills, 75(3), 875-880.

White, S. A., Kavussanu, M., \& Guest, S. M. (1998). Goal Orientations and Perceptions of the Motivational Climate Created by Significant Others. European Journal of Physical Education, 3, 212-228.

Willams, L. (1998). Contextual influences and goal perspectives among female youth sport participants. Research Quarterly for Exercise and Sport, 69(1), 47-57. 
Table 1

Subscale Means and Cronbach's Alphas

\begin{tabular}{lcccc}
\hline \multicolumn{1}{c}{ Subscales } & Mean & SD & $\alpha$ & $\alpha^{*}$ \\
Athlete's Task Orientation & 4.58 & .42 & .62 & .78 \\
Athlete's Ego Orientation & 2.46 & 1.04 & .87 & .88 \\
Mother's Learning \& Enjoyment Climate & 4.36 & .47 & .64 & $.89^{* *}$ \\
Father's Learning \& Enjoyment Climate & 4.41 & .52 & .78 & N/A \\
Mother's Success Without Effort Climate & 2.05 & .81 & .55 & $.87^{* *}$ \\
Father's Success Without Effort Climate & 2.01 & 1.00 & .75 & N/A \\
Mother's Worry Conducive Climate & 2.21 & .93 & .74 & $.91^{* *}$ \\
Father's Worry Conducive Climate & 1.99 & .91 & .80 & N/A \\
Coach's Mastery Climate & 4.46 & .59 & .81 & .78 \\
Coach's Ego Climate & 1.84 & .66 & .70 & .74
\end{tabular}

* Previously Reported Cronbach's Alphas

** Alphas only reported for total subscales

Table 2

Correlations Between Youth Athletes' Achievement Goal

Orientation and Motivational Climate Subscales

\begin{tabular}{lcc}
\hline & Task & Ego \\
Mother's Learning \& Enjoyment Climate & $.25^{*}$ & .03 \\
Father's Learning \& Enjoyment Climate & $.34^{* *}$ & -.04 \\
Mother's Success Without Effort Climate & .02 & $.26^{*}$ \\
Father's Success Without Effort Climate & -.12 & $.35^{* *}$ \\
Mother's Worry Conducive Climate & $-.26^{*}$ & -.05 \\
Father's Worry Conducive Climate & $-.24^{*}$ & .12 \\
Coach's Mastery Climate & $.65^{* *}$ & -.03 \\
Coach's Ego Climate & $-.39^{* *}$ & $.30^{* *}$ \\
$*$ Correlation is significant at the 0.05 level & & \\
$* *$ Correlation is significant at the 0.01 level &
\end{tabular}


Appendix A

Demographic Questionnaire 


\section{Demographic Questionnaire}

Name:

ID Number:

Age:

Grade in School:

Number of Years Playing Basketball:

Number of Years Playing for this Coach:

How many parents do you live with at home (please circle): $\begin{array}{llll}0 & 1 & 2\end{array}$

Which parent, if any, comes to your games most often (please circle):

Mother Father Other:

Which parent, if any, influences your sport participation the most (please circle):

Mother

Father

Other: 
Appendix B

Parent-Initiated Motivational Climate Questionnaire - 2 


\section{Parent-Initiated Motivational Climate Scale - 2}

Please read each of the statements listed below and indicate how much you personally agree with each statement by circling the appropriate response. $1=$ Strongly Disagree, $2=$ Disagree, $3=$

Neutral, 4= Agree, 5= Strongly Agree

\section{I feel that my mother....}

1. Is most satisfied when I learn something new

$\begin{array}{lllll}1 & 2 & 3 & 5\end{array}$

2. Makes me worried about failing.

$\begin{array}{lllll}1 & 2 & 3 & 5\end{array}$

3. Looks satisfied when I win without effort.
1
2
3
4
5

4. Makes me worried about failing because it will appear negative in her eyes.

$\begin{array}{llllll}1 & 2 & 3 & 4 & 5\end{array}$

5. Pays special attention to me whether I'm improving my skills

$\begin{array}{lllll}1 & 2 & 3 & 4\end{array}$

6. Says it is important for me to win without trying hard.

$\begin{array}{lllll}1 & 2 & 3 & 4 & 5\end{array}$

7. Makes sure I learn one thing before teaching me another.

$\begin{array}{lllll}1 & 2 & 3 & 4 & 5\end{array}$

8. Thinks I should achieve a lot without much effort.

$\begin{array}{lllll}1 & 2 & 3 & 4\end{array}$

9. Believes enjoyment is very important in developing new skills

1 
10. Makes me feel badly when I can't do as well as others.

$\begin{array}{lllll}1 & 2 & 3 & 4 & 5\end{array}$

11. Looks completely satisfied when I improve after hard effort..

$\begin{array}{lllll}1 & 2 & 3 & 4 & 5\end{array}$

12. Makes me afraid to make mistakes.

$\begin{array}{lllll}1 & 2 & 3 & 4 & 5\end{array}$

13. Tells me I should be satisfied when I achieve without trying hard.

$\begin{array}{lllll}1 & 2 & 3 & 4 & 5\end{array}$

14. Approves of me enjoying myself when trying to learn new skills

$\begin{array}{lllll}1 & 2 & 3 & 4 & 5\end{array}$

15. Supports my feeling of enjoyment to skill development.

$\begin{array}{lllll}1 & 2 & 3 & 4 & 5\end{array}$

16. Makes me worried about performing skills that I am not good at.

$\begin{array}{lllll}1 & 2 & 3 & 4 & 5\end{array}$

17. Encourages me to enjoy learning new skills.

$\begin{array}{lllll}1 & 2 & 3 & 4 & 5\end{array}$

18. Tells me that making mistakes are part of learning. 
Please read each of the statements listed below and indicate how much you personally agree with each statement by circling the appropriate response. $1=$ Strongly Disagree, $2=$ Disagree, $3=$ Neutral, 4= Agree, 5= Strongly Agree

\section{I feel that my father...}

19. Is most satisfied when I learn something new

$\begin{array}{lllll}1 & 2 & 3 & 4 & 5\end{array}$

20. Makes me worried about failing.

$\begin{array}{lllll}1 & 2 & 3 & 4\end{array}$

21. Looks satisfied when I win without effort.

$\begin{array}{lllll}1 & 2 & 3 & 4 & 5\end{array}$

22. Makes me worried about failing because it will appear negative in her eyes.
1
2
3
4
5

23. Pays special attention to me whether I'm improving my skills
1
2
3
4
5

24. Says it is important for me to win without trying hard.
1
2
3
4
5

25. Makes sure I learn one thing before teaching me another.
1
2
3
4
5

26. Thinks I should achieve a lot without much effort.
1
2
3
4
5

27. Believes enjoyment is very important in developing new skills
1
2
3
4
5

28. Makes me feel badly when I can't do as well as others. 
29. Looks completely satisfied when I improve after hard effort..

$\begin{array}{lllll}1 & 2 & 3 & 4 & 5\end{array}$

30. Makes me afraid to make mistakes.

$\begin{array}{lllll}1 & 2 & 3 & 4 & 5\end{array}$

31. Tells me I should be satisfied when I achieve without trying hard.

$\begin{array}{lllll}1 & 2 & 3 & 4 & 5\end{array}$

32. Approves of me enjoying myself when trying to learn new skills

$\begin{array}{lllll}1 & 2 & 3 & 4 & 5\end{array}$

33. Supports my feeling of enjoyment to skill development.

$\begin{array}{lllll}1 & 2 & 3 & 4 & 5\end{array}$

34. Makes me worried about performing skills that I am not good at.

$\begin{array}{lllll}1 & 2 & 3 & 4\end{array}$

35. Encourages me to enjoy learning new skills.

$\begin{array}{lllll}1 & 2 & 3 & 4 & 5\end{array}$

36. Tells me that making mistakes are part of learning. 
Appendix C

Motivational Climate Scale for Youth Sports 


\section{Motivational Climate Scale for Youth Sports}

Here are some statements about what your current team is like. Please read each one and circle the number that is most correct. If there was more than one coach on your team, the questions are about the coach that you spend most of your time with.

1. Winning games was the most important thing for the coach.
1
2
3
4
5
Not at all True
Somewhat True
Very True

2. The coach made players feel good when they improved a skill.

$\begin{array}{lllll}1 & 2 & 3 & 4 & 5\end{array}$

Not at all True Somewhat True

Very True

3. The coach spent less time with the players who weren't as good.

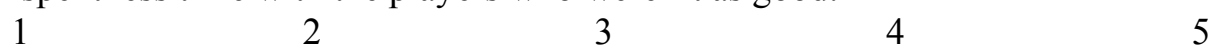

Not at all True Somewhat True Very True

4. The coach encouraged us to learn new skills.

$\begin{array}{ccccc}1 & 2 & 3 & 4 & 5 \\ & \text { Somewhat True } & & \text { Very True }\end{array}$

Not at all True Somewhat True Very True

5. The coach told us which players on the team were the best.
1
2
3
Somewhat True

4

6. The coach told players to help each other get better.

123

Not at all True Somewhat True
4

ost important thing.

Not at all True

\section{2}

(1) ur best was the most
45

Very True

8. The coach paid most attention to the best players.

Somewhat True

4
2

1

Not at all True

Somewhat True

4

9. Coach said that teammates should help each other improve their skills.

12

Not at all True

\section{2}

(1)

3

Somewhat True

10. Players were taken out of games if they made a mistake.

$\begin{array}{ccc}1 & 2 & 3 \\ \text { Not at all True } & & \text { Somewhat True }\end{array}$

11. The coach said that all of us were important to the team's success.

$\begin{array}{ccc}1 & 2 & 3 \\ \text { Not at all True } & & \text { Somewhat True }\end{array}$

12. Coach told us to try to be better than our teammates.

12

Not at all True
2 3

Somewhat True
4

4

Very True

Very True

4

Very True

5

(1)

45

Very True
Very True

Very True

Very Tru

5

Very True 


\section{Appendix D}

Achievement Goal Scale for Youth Sports 


\section{Achievement Goal Scale for Youth Sports}

We want to know what your goals are in sport. Please read each statement and circle the answer that is most correct for you. Remember, there are no right or wrong answers.

1. My goal is to learn new skills and get as good as possible

$\begin{array}{ccccc}1 & 2 & 3 & 4 & 5 \\ \text { Not at all True } & & \text { Somewhat True } & & \text { Very True }\end{array}$

2. The most important thing is to be the best athlete

123

Not at all True

Somewhat True

3. The most important thing is to improve my skills

123

Not at all True

Somewhat True

4. My goal is to improve so I am better than others

$\begin{array}{ccc}1 & 2 & 3 \\ \text { Not at all True } & \text { Somewhat True }\end{array}$

5. I work hard to become the best I can be

$1 \quad 2 \quad 3$

Not at all True

Somewhat True

6. I want to be better than others at my sport

$$
1
$$

Not at all True

7. I feel successful when I learn new skills

$1 \quad 2 \quad 3$

Not at all True Somewhat True

8. To me, success means being better than others

$\begin{array}{ccc}1 & 2 & 3 \\ \text { Not at all True } & & \text { Somewhat True }\end{array}$

9. I feel successful when I do my best

$\begin{array}{ccc}1 & 2 & 3 \\ \text { Not at all True } & & \text { Somewhat True }\end{array}$

10. I want to show that I am better than others

$\begin{array}{cc}1 & 2 \\ \text { Not at all True } & \end{array}$

11. My goal is to master the skills in my sport

$\begin{array}{ccc}1 & 2 & 3 \\ \text { Not at all True } & & \text { Somewhat True }\end{array}$

12. My goal is to be better than others in my sport

$\begin{array}{ccc}1 & 2 & 3 \\ \text { Not at all True } & & \text { Somewhat True }\end{array}$

4

4

$4 \quad 5$

Very True

4

5

Very True

4

5

Very True

4

5

Very True

4

4

4

Somewhat True

4

Very True

4

5

Very True 
Appendix E

IRB Approval 
Pete Kadushin <pete.kadushin@gmail.com>

\section{BRAAN2: New IRB Protocol Approved}

1 message

wvuecomp@wvu.edu <wvuecomp@wvu.edu>

Mon, Oct 18, 2010 at 4:16 PM

To: DCClement@mail.wvu.edu, pkadushi@mix.wvu.edu

The following new IRB Protocol has been approved.

Tracking \#: H-22747

PI: Clement, Damien

Title: Perceptions of Parent-Initiated and Coach-Created Motivational Climate and their Influence on Youth Achievement Goal Orientation

Approval Date: 10/18/2010

Expiration Date: 10/17/2011

The BRAAN2 website can be accessed by clicking the following link: BRAAN2 Login 
Appendix F 


\section{Youth Basketball Research Study}

Julian Jacquez <jjaquez@bcntele.com>

Mon, Sep 13, 2010 at 9:06 AM

To: Pete Kadushin <pkadushi@mix.wvu.edu>

Peter,

The North Basketball League would enjoy supporting your research efforts. Our league generally begins in mid November with a player workout/team assignment session. Once teams are established there are a couple weeks of practice. Our season generally starts in early December and runs through end of February.

Here are some initial thoughts/questions:

What age group do you want to include - 3rd/4th, 5th/6th or both?

Do you want to plan to complete your study before the Christmas break or after? Basically at the start of the league or toward the completion of the league.

Do you want to attend and observe the player workout and team drafting session?

We will want to see the nature of the questions and interaction that will occur to support the study.

You will need to create a schedule of what you need to have done that we can work from.

We can discuss these topics in a conversation.

Best regards,

Julian Jacquez

304-612-3877

From: pete.kadushin@gmail.com [pete.kadushin@gmail.com] On Behalf Of Pete Kadushin [pkadushi@mix.wvu.edu] Sent: Saturday, September 11, 2010 1:47 PM

To: Julian Jacquez

Subject: Youth Basketball Research Study

[Quoted text hidden] 
Pete Kadushin <pete.kadushin@gmail.com>

\section{Westside Basketball League}

\section{Reggie and Shelley <reggieandshelley@comcast.net>}

To: pkadushi@mix.wvu.edu

Peter,

Attached is the practice schedule for the Westside Basketball League. Feel free to contact the coaches in the 3/4 and 5/6 grade divisions about participating in your study. The Westside Basketball League grants you access to the coaches which in turn with parental permission our athletes may participate in the study.

If you have any questions or if I can be of further assistance feel free to contact me.

Shelley Martin

Secretary

Westside Basketball League

3043286060

WestsideBasketballLeaue2010PracticeSchedule.xls

$30 \mathrm{~K}$ 
Appendix G

Parental Consent Form 


\title{
WestVirginiaUniversity.
}

Office of Research Compliance

\section{PARENTAL OR GUARDIAN CONSENT AND INFORMATION FORM}

\author{
Parental Consent Form
}

\section{Principal Investigator: Clement, Damien \\ Department: Physical Education \\ Tracking Number: $\quad \mathrm{H}-22747$}

\section{Study Title:}

Perceptions of Parent-Initiated and Coach-Created Motivational Climate and their Influence on Youth Achievement Goal Orientation

\section{Co-Investigator(s):}

Kadushin, Peter,

\section{Sponsor}

\section{Contact Persons}

In the event your child experiences any side effects or injury related to this research, you should contact Peter Kadushin, 413/636-5288;

pkadushi@mix.wvu.edu, or his supervisor, Dr. Damien Clement, 304/2930863; damien.clement@mail.wvu.edu.

If you have any questions, concerns, or complaints about this research, you can contact Peter Kadushin, 413/636-5288; pkadushi@mix.wvu.edu, or his supervisor, Dr. Damien Clement, 304/293-0863;

damien.clement@mail.wvu.edu.

In addition if you would like to discuss problems, concerns, have suggestions related to research, or would like to offer input about the research, contact the Office of Research Integrity and Compliance at 304293-7073.

For information regarding your rights as a research subject, you may contact the Office of

\begin{tabular}{lll}
\hline Tracking \#: & $\mathrm{H}-22747$ & Page 1 of 6 \\
Approved On: & $10 / 18 / 2010$ & \\
Valid Through: & $10 / 17 / 2011$ & \\
Last Amended: & $11 / 12 / 2010$ &
\end{tabular}

$$
\overline{\text { Initials }} \overline{\text { Date }}
$$


Tracking \#: $\mathrm{H}-22747$

Research Compliance at 304/293-7073.

\section{Introduction}

You, have been asked to allow your child to participate in this study, which has been explained

to you and your child by Peter Kadushin, B.S. This study is being conducted by Peter Kadushin, B.S. and Dr. Damien Clement, Ph.D. in the College of Physical Activity and Sport Science at West Virginia University. This research is being conducted to fulfill the requirements for a Master's Thesis in Sport and Exercise Psychology in the Department of Sport Psychology at West Virginia University, under the supervision of Dr. Damien Clement, Ph.D.

\section{Purposes of the Study}

The purpose is to learn more about the relationship between parents ' and coaches' thoughts and behaviors regarding success and how they influence youth athletes' beliefs about success.

\section{Description of Procedures}

This study involves answering four short questionnaires and will take approximately twenty to thirty minutes for your child to complete. Your child will be asked to fill out questionnaires regarding parents behaviors about success, coaches behaviors about success, the participant's beliefs about success, and a short demographic information questionnaire. The first three questionnaires will be answered either before or after registration or a practice session. The final questionnaire will be answered either before or after a game or practice roughly a month later. Your child does not have to answer all the questions. You will have the opportunity to see the questionnaires before signing this consent form.

The study will be performed at North Elementary School. Approximately 106 subjects are expected to participate in this study.

\section{Risks and Discomforts}

There are no known or expected risks to your child from participating in this study, except for the mild frustration associated with answering the questions.

$\begin{array}{lll}\text { Tracking \#: } & \mathrm{H}-22747 & \text { Page } 2 \text { of } 6 \\ \text { Approved On: } & 10 / 18 / 2010 & \\ \text { Valid Through: } & 10 / 17 / 2011 & \\ \text { Last Amended: } & 11 / 12 / 2010 & \end{array}$

$$
\overline{\text { Initials }} \overline{\text { Date }}
$$




\section{Alternatives}

Your child does not have to participate in this study.

Alternatives that could be considered in your child's case include not participating in the study.

\section{Benefits}

Your child may not receive any direct benefit from this study. The knowledge gained from this study may eventually benefit others.

\section{Financial Considerations}

No payments will be made for participating in the study.

\section{Confidentiality}

Any information about your child that is obtained as a result of participation in this research will be kept as confidential as legally possible.

Your child's research records and test results, just like hospital records, may be subpoenaed by court order or may be inspected by federal regulatory authorities without your additional consent.

In any publications that result from this research, neither your child's name nor any information from which your child might be identified will be published without your consent.

You can decide to sign or not to sign this authorization section. However, if you choose not to sign this authorization, your child will not be able to take part in the research study. Whatever choice you make about this research study, it will not have an effect on your child's opportunity to participate in the league.

The information is being disclosed for the following reasons:

- Publication of study results (without identifying your child)

You may cancel this authorization at any time by writing to the

\begin{tabular}{lll}
\hline Tracking \#: & H-22747 & Page 3 of 6 \\
Approved On: & $10 / 18 / 2010$ & \\
Valid Through: & $10 / 17 / 2011$ & \\
Last Amended: & $11 / 12 / 2010$ &
\end{tabular}

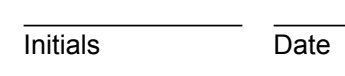


Tracking \#:

\section{Principal Investigator: \\ Dr. Damien Clement \\ Physical Activity and Sport Sciences \\ PO Box 6116 \\ Morgantown, WV, 26506-6116}

If you cancel this authorization, any information that was collected already for this study cannot be withdrawn. Once information is disclosed, according to this authorization the recipient may redisclose it and then the information may no longer be protected by federal privacy regulations.

This authorization will not expire unless you cancel it.

\section{SIGNATURE}

I have read this section and all of my questions have been answered. By signing below, I acknowledge that I have read and accept all of the above.

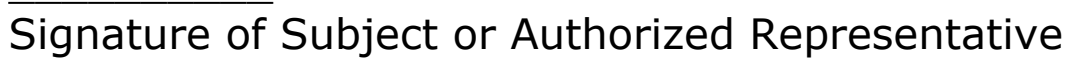

Date

Print Name of Subject or Authorized Representative

\section{Voluntary Participation}

Participation in this study is voluntary.

You or your child may refuse to participate in this study. You or your child may withdraw from this study at any time.

Refusal to participate or withdrawal will involve no penalty to you or your child.

In the event new information becomes available that may affect your willingness to allow your child to participate in this study, this information will be given to you so that you can make an informed decision about whether or not to continue your child's participation.

You have been given the opportunity to ask questions about the research, and have received answers concerning areas you did not understand.

ASSENT: (Statement of person conducting assent discussion)

1. I have explained all aspects of the research to the subject to the best of his or her ability to understand.

\begin{tabular}{lll}
\hline Tracking \#: & $\mathrm{H}-22747$ & Page 4 of 6 \\
Approved On: & $10 / 18 / 2010$ & \\
Valid Through: & $10 / 17 / 2011$ & \\
Last Amended: & $11 / 12 / 2010$ &
\end{tabular}

$$
\overline{\text { Initials }} \overline{\text { Date }}
$$


2. I have answered all the questions of the subject relating to this research.

3. The subject agrees to be in the research.

4. I believe the subject's decision to enroll is voluntary.

5. The study staff agree to respect the subject's physical or emotional dissent at any time during this research when that dissent pertains to anything being done solely for the purpose of this research.

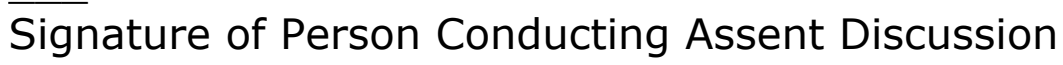

Date

\section{Statement of Parent/Guardian:}

My child appears to understand the research to the best of his or her ability and has agreed to participate.

Signature of Parent/Guardian

Date

Tracking \#:

Approved On:

Valid Through:

Last Amended:
Page 5 of 6

Initials

Date 
Upon signing this form, you will receive a copy.

I willingly consent to allow my child to participate in this research.

Signature of Parent or Guardian Printed Name

Date Time

The parent/guardian has had the opportunity to have questions addressed. The parent/guardian willingly agrees to allow his/her child to be in the study.

Signature of Investigator or

Printed Name

Date

Time

Co-Investigator

$\begin{array}{lll}\text { Tracking \#: } & \text { H-22747 } & \text { Page } 6 \text { of } 6 \\ \text { Approved On: } & 10 / 18 / 2010 & \\ \text { Valid Through: } & 10 / 17 / 2011 & \\ \text { Last Amended: } & 11 / 12 / 2010 & \end{array}$

$\overline{\text { Initials }} \overline{\text { Date }}$


Appendix $\mathrm{H}$

Assent Form 


\section{WestVurginiaUniversity.}

Office of Research Compliance

\section{ASSENT FORM}

Assent Form

Principal Investigator: Clement, Damien

Department: Physical Education

Tracking Number: $\quad \mathrm{H}-22747$

\section{Study Title:}

Perceptions of Parent-Initiated and Coach-Created Motivational Climate and their Influence on Youth Achievement Goal Orientation

\section{Co-Investigator(s):}

Kadushin, Peter,

\section{Sponsor}

\section{Contact Persons}

In the event you experience any side effects or injury related to this research, you should contact Peter Kadushin, 413/636-5288;

pkadushi@mix.wvu.edu, or his supervisor, Dr. Damien Clement, 304/2930863; damien.clement@mail.wvu.edu.

If you have any questions, concerns, or complaints about this research, you can contact Peter Kadushin, 413/636-5288; pkadushi@mix.wvu.edu, or his supervisor, Dr. Damien Clement, 304/293-0863; damien.clement@m ail.wvu.edu.

In addition if you would like to discuss problems, concerns, have suggestions related to research, or would like to offer input about the research, contact the Office of Research Integrity and Compliance at 304293-7073.

$\begin{array}{lll}\text { Tracking \#: } & \mathrm{H}-22747 & \text { Page } 1 \text { of } 4 \\ \text { Approved On: } & 10 / 18 / 2010 & \\ \text { Valid Through: } & 10 / 17 / 2011 & \\ \text { Last Amended: } & 11 / 12 / 2010 & \end{array}$


Tracking \#: $\mathrm{H}-22747$

For information regarding your rights as a research subject, you may contact the Office of Research Compliance at 304/293-7073.

\section{Introduction}

You, have been asked to be in this research study, which has been explained to you by Peter Kadushin, B.S.

\section{Purposes of the Study}

You have been told that the purpose of this study is to learn more about parents' and coaches' thoughts and behaviors about success and how that affects youth athletes' beliefs about success.

\section{Description of Procedures}

This study will be done at Gym. You will be asked some questions. It will take about thirty minutes for you to answer the questions. You will answer questions at two different times, once during before try-outs or your practice and another time roughly a month later. You may see the questions before signing this page. You do not have to answer all of the questions.

\section{Discomforts}

Some of the questions will be difficult and you may not enjoy trying to answer them.

\section{Benefits}

This study may not help you, but what they learn from the study may help other people.

\section{Confidentiality}

We promise that anything we learn about you in this study will be kept as secret as possible.

\section{Voluntary Participation}

You do not have to do this. No one will be mad at you if you refuse to do

$\begin{array}{lll}\text { Tracking \#: } & \text { H-22747 } & \text { Page } 2 \text { of } 4 \\ \text { Approved On: } & 10 / 18 / 2010 & \\ \text { Valid Through: } & 10 / 17 / 2011 & \\ \text { Last Amended: } & 11 / 12 / 2010 & \end{array}$

$\overline{\text { Initials }} \overline{\text { Date }}$


Tracking \#:

$\mathrm{H}-22747$

this or if you decide to quit. You have been allowed to ask questions about the research, and all of your questions were answered. Your standing in the basketball league will not be affected if you choose not to do this study.

$\begin{array}{lll}\text { Tracking \#: } & \mathrm{H}-22747 & \text { Page } 3 \text { of } 4 \\ \text { Approved On: } & 10 / 18 / 2010 & \\ \text { Valid Through: } & 10 / 17 / 2011 & \\ \text { Last Amended: } & 11 / 12 / 2010 & \end{array}$


Tracking \#:

I willingly agree to be in this research.

Signature of Subject Printed Name

Date Time

The child has had the opportunity to have questions addressed. The child willingly agrees to be in the study.

$\begin{array}{lll}\text { Tracking \#: } & \mathrm{H}-22747 & \text { Page } 4 \text { of } 4 \\ \text { Approved On: } & 10 / 18 / 2010 & \\ \text { Valid Through: } & 10 / 17 / 2011 & \\ \text { Last Amended: } & 11 / 12 / 2010 & \end{array}$


The purpose of the following literature review is to examine the previous research that has been done on: a) socialization and the influence that parents and coaches can have on the youth athlete sport experience; b) achievement goal orientation and its influence on psychosocial outcomes in youth sports; and c) motivational climate and how it may be influenced by parents and coaches.

\section{Socialization}

Literature investigating the socializing influence of significant others (e.g., parents, coaches, peers) on children, and youth athletes in particular, has revealed some interesting findings. In a review of the socialization literature, Brustad (1992) attempted to describe the various ways that significant others might influence youth athletes. Sport performance is a very visible endeavor, with parents and coaches often having the opportunity to be closely involved with the sporting experience. The sport setting also provides an opportunity for these significant others to provide direct feedback, which may help to explain how parents and coaches can communicate their beliefs about success (Brustad, 1992).

More specifically, Brustad (1992) suggests that parents' and coaches' own achievement goal orientation very likely informs their evaluation of a child's performance, which may help to communicate the significant other's beliefs about success to the child. The child's behaviors are subsequently reinforced, aiding in the transfer of achievement goal orientation from significant others to youth athletes (Brustad, 1992).

Looking at the developmental literature that investigates the changing relationship between youth athletes and significant others, it is suggested that as youth athletes enter adolescence, the degree to which parents play a role in communicating important socializing 
information may decrease. Horn and Hasbrook (1986) conducted a study that examined this changing relationship. The authors reported that young children $(8-11$ years old $)$ displayed a preference for external sources of information, including adult feedback, whereas early adolescents were more likely to use social comparison as their measure of competence. This shift was highlighted by Fuligni and Eccles (1993), who explained that consistent with a shift in developmental needs during the transition from youth to adolescence, there is also a change in emphasis from parents being the primary socializer to an increased emphasis on peers and others. With the changing needs of athletes as they move into adolescence, it is important for researchers to be aware of the shifting dynamic between parents, coaches, and youth athletes when investigating youth sports. It is also necessary to be aware of the different ways that parents and coaches may influence youth athletes' sport experience. Many researchers have used achievement goal theory as a way of assessing the influence that parents and coaches have on these athletes.

\section{$\underline{\text { Achievement Goal Orientation }}$}

Achievement goal theory has been used in different settings as a way to assess an individual's beliefs about success. How individuals attribute success can provide valuable information for researchers who are interested in studying motivation, feelings of competence, and self-esteem in various settings (Barnett, Smoll, \& Smith, 1992; Black \& Weiss, 1992; Duda \& Nicholls, 1992; Smoll, Smith, \& Cumming, 2007; Vazou, Ntoumanis, \& Duda, 2006). Achievement goal theory describes two orthogonal constructs; ego and task orientation. These goal orientations impact the ways an individual views the strategies used in achievement situations, how they expend effort, and which tasks an individual chooses (Ames, 1992; 
Nicholls, 1984;). Furthermore, Nicholls (1984) conceived the achievement goal theory as a developmental theory, and predicted youth would be more likely to use self-referenced criteria to determine success, and thus more task oriented.

When ability and task difficulty are judged by referencing the ability of other members or a normative reference group, an individual is said to be "ego oriented" (Nicholls, 1984) or performance oriented (Ames, 1992). For an ego-oriented individual, effort is seen as less important, and success with little effort can be the cause of satisfaction (Givvin, 2001). Individuals with an ego orientation are likely to approach tasks in which either a high competence evaluation is guaranteed, or a low competence evaluation can be avoided, and may exhibit failure-avoiding patterns of motivation (Nicholls, 1984).

In contrast, when ability and task difficulty are judged relative to one's own understanding, perceived mastery, or knowledge an individual is said to be task oriented (Nicholls, 1984) or mastery oriented (Ames, 1992). For a task-oriented individual, effort is believed to be the means towards reaching a desired end and success is defined as improvement rather than victory over an opponent. Task-oriented individuals will also perceive errors to be non-threatening and believe obstacles to be cues that alternate strategies or increased effort is necessary (Givvin, 2001). In broad terms, an individual who is task oriented is more likely to choose moderately challenging tasks, persist at those tasks, and exert maximum effort when compared to ego oriented individuals (Nicholls, 1984). In the achievement goal theory literature, there is a lack of consensus on which terms are most appropriate, but for the purposes of this review, the terms task-oriented and ego-oriented will be used. Several researchers have investigated the application of achievement goal theory in both academic and sport settings to 
help understand motivation and achievement behaviors in youth and adults (Ames, 1992; Duda \& Nicholls, 1992; Givvin, 2001; Williams, 1998)

Duda and Nicholls (1992) conducted an exploratory study on achievement goal theory in both the classroom and sports, in an effort to establish a connection between goal orientations and beliefs about success. The authors hypothesized that individuals asked to report their sportrelated achievement goal orientation would be more likely to be ego oriented because competition is a defining feature of the environment. The purpose of the study was to investigate what adolescents believed were the causes of success in both the classroom and athletic domain. The Motivational Orientation Scales (MOS) used to assess goal orientations in 99 males and 198 females with a mean age of 15.1 years. The scale consisted of 21 items specific to classroom participation, and 21 parallel items that reflected the athletic setting. Both scales used a 5-point Likert scale from 1 (strongly agree) to 5 (strongly disagree). To assess beliefs about success, the authors used two 20-item questionnaires, asking participants to rate their agreement with each item.

Correlational analyses were used to identify the beliefs of success that were related to task and ego orientations. Results revealed that task orientation and beliefs of success due to collaboration and effort were matched, while ego orientation was related to beliefs that success required attempts to defeat others and superior ability. No differences were found between beliefs about success and goal orientations across the academic and athletic domains, contradicting the authors' hypothesis (Duda \& Nicholls, 1992). These findings were congruent with the tenets of achievement goal theory, which stated that ego-oriented individuals would compare their ability to the ability of others to define success, while task-oriented individuals would be more likely to view hard work and improvement as success (Nicholls, 1984). 
In order to explore the specific relationship between parents' goal orientations and their sons, Bergin and Habusta (2004) investigated a sample of 123 male hockey players (10-13 years of age) along with 57 mothers and 65 fathers. The athletes were given two copies of the Task and Ego Orientation in Sport Questionnaire (TEOSQ) and were asked to fill out one to describe their goal orientation and a second to describe the goal orientation of the parent who was most actively involved in the athlete's hockey participation. The parent was also asked to fill out two copies of the TEOSQ, one for themselves and another for their child's perceived goal orientation.

The results found a moderate significant correlation between parents reported ego orientation and their sons reported ego orientation $(r=0.44, p<0.001)$, while the correlation between reported task orientation for parents and sons was not significant $(r=0.08)$. However, athletes' self-reported goal orientations correlated strongly with perceived parental goal orientation for both task $(r=0.57, p<0.001)$ and ego $(r=0.66, p<0.001)$ orientations.

Similar results were found for parents self-reported goal orientations and their perceptions of their sons goal orientations for both task $(r=0.55, p<0.001)$ and ego $(r=0.66, p$ $<0.001)$ orientations. There were no differences across gender for parents reported goal orientations or for athletes' perceptions of their parents' goal orientations. These results were congruent with previous research (Smoll \& Smith, 1989; Babkes \& Weiss, 1999), with perceptions of parental goal orientation having a stronger relationship to athletes' reported goal orientations than parents' self-reported orientations.

As research in the field has developed, researchers have looked to examine not only the goal orientations that parents may communicate to their children, but also the motivational climate they may create which may provide a pathway for these goal orientations to be communicated. 
In an effort to understand the extent to which situational factors, perceptions of the goal orientations of parents, and self-perception of goal orientations predicted goal orientations in youth athletes, Ebbeck and Becker (1994) studied a group of youth sport athletes participating in a local soccer league. A sample of 75 males and 91 females $(M=12$ years old) were given the TEOSQ and Perceived Motivational Climate in Sport Scale - 2 (PMCSQ-2) to assess goal orientation as well as self-perceived motivational climate. The participants were also asked to complete a modified TEOSQ two additional times to obtain their perceptions of the goal orientations of their mother and father. Self-esteem and soccer competence were measured using the self-worth and athletic competence subscales from the Self-Perception Profile for Children.

A canonical correlation was used to analyze the relationship between youth athlete goal orientation, situational factors, and perceived parental goal orientation. More specifically, Ebbeck and Becker (1994) looked at various factors that were associated with an athletes' task or ego orientation. Increased soccer competence, and perceived parental task and ego orientation were associated with athletes' ego orientations. Soccer competence, perceptions of parental task orientation, and perceptions of a mastery climate were associated with athletes' task orientation.

It is important to note that perceived parent goal orientation was the dominant predictor of youth athlete goal orientation (Ebbeck \& Becker, 1994). When comparing perceived parental goal orientation, athletes did not perceive a difference between mothers and fathers. The results of this study support previous research suggesting that parents can have a significant influence on their children's goal orientations (Brustad, 1992).

Sage and Kavussanu (2007) extended the goal orientation research to examine the effect of goal orientations on moral behavior in youth soccer players. The authors hypothesized that task orientation would be correlated with prosocial behavior while ego orientation would be 
correlated with antisocial behavior. Prosocial behavior was defined as behaviors that were fair and behaviors that benefited others, while antisocial behavior was defined as behavior that is meant to harm or impair another (Sage \& Kavussanu, 2007). The authors administered the Perceptions of Success Questionnaire (PSQ) to 227 male and 138 female youth soccer athletes $(M=13.4$ years old). The scale used 12 items ( 6 task and 6 ego) and a 5-point Likert scale (from strongly disagree to strongly agree). The alpha coefficient for both subscales was 0.88 . Moral behaviors were assessed using a scale developed in a previous study by Sage and colleagues, and gave examples of 8 prosocial and 13 antisocial behaviors. Participants were asked to rate the frequency with which they engaged in each of the behaviors using a 5-point Likert scale (from never to very often). Examples of items included "Deliberately hitting or kicking an opponent" and "Apologizing to an opponent after fouling him or her."

A hierarchical regression analysis was used to assess the degree to which goal orientations were found to contribute to moral behavior. It was found that task orientation contributed to $7 \%$ of the variance in prosocial behavior, while the combination of a high ego orientation and a low task orientation contributed $7 \%$ of the variance in antisocial behavior. Sage and Kavussanu (2007) suggested that prosocial behavior may reflect the qualities of task orientation in that prosocial behavior towards both opponents and teammates may create a supportive environment that emphasizes group development and learning. The authors explained the relationship between antisocial behavior and ego orientation by pointing out that the win-atall-costs mentality often found in ego oriented individuals may lead them to engage in behaviors that illegally or amorally allow them to gain an advantage over opponents. Further, the negative correlation between task orientation and antisocial behavior was expected because antisocial 
behavior may detract from the attention that may help self-referenced improvement (Sage \& Kavussanu, 2007).

The results of this study have important practical implications, as it provides researchers with an opportunity to create interventions that promote prosocial behaviors. Sage and Kavussanu (2007) recommend that significant others, including coaches, parents, and sport psychology consultants encourage task orientations, resulting in increased prosocial behavior. Other studies have examined the potential ways that significant others can influence goal orientations in youth athletes.

Based on the achievement goal theory research, there has been a connection established between parents' achievement goal orientations and those of their children (Bergin \& Habusta, 2004; Ebbeck \& Becker, 1994) and that an athlete's achievement goal orientation is related to many outcome behaviors (i.e., collaborative vs. competitive behaviors, prosocial vs. antisocial behaviors). While much of the research has focused on parents' and coaches' beliefs about success, studies have also begun to look at the motivational climate (i.e., environment and situational factors) that is created for youth athletes, and how that impacts their achievement goal orientation.

\section{$\underline{\text { Motivational Climate }}$}

It has been proposed by some researchers that the situational factors that surround an individual and create the environment in which they perform have the potential to influence their beliefs about success (i.e., achievement goal orientation). Ames (1992) investigated the effect that varied classroom environments had on students' beliefs about success, with results showing a connection between the environment and attitudes towards success. This construct has come to 
be called motivational climate (Ames, 1992). Motivational climate can be conceptualized in two different ways. A mastery climate is one in which significant others define success in terms of task mastery, exhibiting maximum effort, and self-improvement (Ames, 1992). This is contrasted with a performance climate, where social comparison is promoted as a basis for judgments of success, which in turn may lead to an ego orientation. It is important to note that motivational climate is a situational construct, which is in part created by the significant others surrounding the performer (e.g., parents, coaches, peers). In order to fully understand the relationship between motivational climate and achievement goal orientation, it is necessary to examine the influence that these significant others, more specifically parents and coaches, have on athletes' perceptions of motivational climate.

White (1996) investigated the relationship between perceptions of parent-initiated motivational climate and self-reported achievement goal orientation in a sample of female volleyball players ( $N=204, M=15.40$ years old). The participants were given the TEOSQ and the Parent-Initiated Motivational Climate Questionnaire - 2 (PIMCQ-2) in order to assess their achievement goal orientation and perceptions of parent-initiated motivational climate respectively. It was hypothesized that the learning/enjoyment subscale of the PIMCQ-2 would be a significant predictor of self-reported task orientation, while the worry-conducive climate and success-without-effort subscales would be significant predictors of self-reported ego orientation.

Stepwise multiple regression analyses were used to examine the relationship between perceptions of parent-initiated motivational climate and youth athletes' self-reported achievement goal orientation. Consistent with previous research, White (1996) found that perceptions of being rewarded for success without effort predicted $14 \%$ of the variance in self- 
reported ego orientation. Furthermore, perceptions of a learning/enjoyment climate predicted $27 \%$ of the variance in self-reported task orientation. These results are congruent with achievement goal theory and the construct of motivational climate, showing a link between youth athletes' achievement goal orientation and their perceptions of motivational climate.

Based on the orthogonal nature of achievement goal orientations, White (1998) extended her motivational climate research by creating four different goal orientation profiles in an effort to better understand the relationship between perceived parental motivational climate, youth athlete goal orientations and competitive trait anxiety. The four goal orientation profiles were high task/high ego, high task/low ego, low task/high ego, and low task/low ego. It was hypothesized that participants with a low task/high ego profile would perceive a performance climate from their parents, whereas participants with a high task/low ego profile would see parents as creating a mastery climate and have low levels of competitive trait anxiety.

A sample of 130 males and 149 females $(M=14.28$ years old $)$ who played on a sports team (i.e., football, basketball, baseball, volleyball, softball, and soccer) were given a four section inventory including demographic information, the TEOSQ, the PIMCQ-2, and the Sport Competition Anxiety Test-Adult. The PIMCQ-2 contains three subscales; learning and enjoyment, worry-conducive, and success-without-effort.

In order to support the orthogonality of task and ego constructs, a correlation analysis was conducted comparing the task and ego subscales of the TEOSQ, with a small, nonsignificant correlation coefficient $(r=0.109)$. A one-way MANOVA was used to test the four goal orientation profiles for differences in views about perceived parental motivational climate and levels of competitive trait anxiety. The results showed that both high task groups, when 
compared to low task groups, perceived that their parents endorsed a mastery motivational climate.

In comparison, the low task/high ego group was compared to the high task/low ego group, and found to perceive their mother valued a performance climate (success with low effort), and their fathers were perceived to cause worry about making mistakes. The same group experienced the highest levels of competitive trait anxiety. With the low task/high ego group also reporting the highest levels of competitive trait anxiety, the importance of promoting task orientations in youth and adolescent athletes was highlighted.

The high task/high ego group reported perceptions of both mastery and performance climates created by their parents. Specifically, while participants perceived a climate where enjoyment and learning were encouraged, they also perceived their mother as causing fear of making mistakes and fathers emphasizing a climate where success was accompanied by low levels of effort. It is important to note that few studies have adopted the 'goal profile' approach employed by White (1998), which may provide additional insight into the relationship between achievement goal orientation and motivational climate.

Waldron and Krane (2005) hypothesized that coach and parent mastery climates would predict athletes' task orientation, while performance climates would be positively related to athletes' ego orientation. The authors also hypothesized that when perceptions of coach and parent created motivational climate were congruent, the related goal orientation would become strengthened for youth athletes (Waldron \& Krane, 2005).

The study assessed perceptions of coach and parent created motivational climate and goal orientations in 62 female softball players $(M=15$ years old; Waldron \& Krane, 2005). During an early season data collection, participants completed the TEOSQ as well as a demographic 
questionnaire. During a late season data collection, the athletes completed the TEOSQ, PIMCQ, and the PMCSQ-2, in order to assess their goal orientations, parents' perceived motivational climate, and coaches' perceived motivational climate respectively.

A forced-entry regression analysis was used for each late season goal orientation in order to assess the predictors of late season goal orientation. For late season task orientation, early season task orientation (34\%) perceptions of a parent-initiated mastery climate $(5 \%)$ and perceptions of coach created mastery climate (12\%) all contributed significantly to variance. For late season ego orientation, only early season ego orientation (42\%) was a significant predictor of variance. These results are congruent with previous studies (Williams, 1998), which assessed general perceptions of motivational climate, and also found early season ego orientation to be the single significant predictor of late season ego orientation.

To assess whether goal orientations changed over the course of a season, two paired ttests were used, with the alpha level set at 0.025 to control for potentially inflated Type I error (Waldron \& Krane, 2005). Task orientation did not change significantly during the season, while ego orientation significantly decreased from early season to late season $(t(61)=2.80, p=0.006$, $d=0.28$; Waldron \& Krane, 2005). This study supported previous research suggesting that significant others can have an impact on youth athletes' goal orientations.

Several studies have examined the influence of motivational climate on athletes' achievement goal orientation. Using a descriptive methodology, Williams (1998) attempted to assess the impact that perceived motivational climate had on goal orientations in youth softball players. Female softball players $(N=127 ; M=13$ years old $)$ completed the TEOSQ and the PMCSQ-2 in order to understand both goal orientations and their perceptions of motivational climate. Goal orientation was assessed in the first two weeks of the season, as well as during the 
last week of the season. In addition the PMCSQ-2 was administered during the late-season data collection.

A force-entry hierarchical regression analysis was used to determine the amount of influence motivational climate had on changes in goal orientation. For late-season task orientation, a mastery motivational climate accounted for $11 \%$ of the variance, while early season task orientation contributed $19 \%$ of the variance. For late-season ego orientation, the only significant predictor was early season ego orientation, accounting for $30 \%$ of the variance. These results are congruent with the Nicholls' (1984) theory that goal orientations are for the most part dispositional, and are difficult to change. However, the study still indicated that a degree of change in goal orientation throughout a season was related to athletes' perceived motivational climate, providing support for interventions that hope to alter motivational climate in an effort to positively impact task orientation in youth athletes. Other researchers have suggested that the reason motivational climate had no significant impact on athletes' ego orientation is due to the competitive nature of the sport setting, arguing that it may be more difficult to influence ego orientation in athletes (Waldron \& Krane, 2005).

Smith, Smoll, and Cumming (2009) performed a descriptive study looking to further characterize the relationship between motivational climate and achievement goal orientation in youth sports athletes. The purpose of the study was to investigate whether or not short-term exposure to either motivational climate in a youth sport setting would influence changes in achievement goal orientation (Smith et al., 2009). It was hypothesized that athletes in a mastery climate would exhibit increases in task goal orientation throughout the season.

A sample of male and female basketball players $(N=290)$ was used in this study. Gender breakdown was as follows: boys $(n=145)$ and girls $(n=98)$ with a mean age of 11.28 years old. 
Participants were given the Achievement Goal Scale for Youth Sports (AGSYS) during the first week of the season and again twelve weeks later at the end of the season. The Motivational Climate Scale for Youth Sports (MCSYS) was administered during the second time point as well. The results of the study supported the hypotheses proposed by the authors, showing that athletes who perceived a mastery climate were more likely to report a task orientation at the end of the season, and athletes who perceived a performance climate were more likely to report an ego orientation at the end of the season. These results further strengthen the connection between motivational climate and the resulting achievement goal orientation that athletes report throughout a season (Smith et al., 2009).

Building from previous research into the impact that coaches have on motivational climate, Smoll et al. (2007) combined previous coaching interventions with aspects of achievement goal theory to create an intervention called the Mastery Approach to Coaching (MAC). The intervention was designed to increase coaching behaviors, such as reinforcement for effort and encouragement after mistakes, which would promote a mastery climate. The purpose of the study was to investigate the impact of a MAC intervention on motivational climate and the effect this had on the achievement goal orientations of youth athletes. Smoll et al. (2007) hypothesized that athletes whose coaches had undergone MAC training would increase in mastery goal orientation.

The sample consisted of coaches $(N=37)$ and athletes $(N=225)$ was used, with the boys $(n=126)$ and girls $(n=99)$ having a mean age of 11.50 years old. The mean age of the athletes was 11.5. The coaches were split into an experimental group (10 boys' and 10 girls' teams) and a control group (9 boys' and 8 girls' teams). In order to assess motivational climate, the 12-item MCSYS was used. To measure achievement goal orientation the AGSYS was used. Both 
measures had previously been developed and tested for reliability and validity by the authors (Smoll et al., 2007). The experimental group coaches then participated in a 75-min MAC workshop. The AGSYS was administered at two points, one prior to the beginning of the season, and one during the final week of competition. During the final week, athletes also completed the MCSYS.

Results of the study showed that athletes who played for trained coaches reported significantly higher levels of mastery-climate promoting behaviors from their coaches and lower levels of performance climate promoting behaviors. However, an increase in mastery climate behaviors does not necessarily indicate a change in the goal orientation of the athletes. Results of the AGSYS across time showed that athletes who played for coaches in the experimental group showed an increase in task orientation scores from preseason to the end of the season. Smoll et al. (2007) attributed this increase in task orientation to the way coaches defined success (skill mastery as opposed to winning) and that over time such criteria for success may be internalized by the athletes in a mastery climate and lead to adjusted achievement goal orientations.

This study provides further support for the belief that the sport experience (in the form of achievement goal orientation and the resulting outcomes) can be positively impacted through coaching behavior interventions and reinforces the need for continued research into the relationship between significant others, motivational climate, and youth sport athletes.

Building off the work of Brustad (1992) and Ames (1992), researchers began to investigate the connection between young athletes' goal orientations and those of their significant others. Givvin (2001) included both coaches and parents in a study that examined the extent to which goal orientations of young athletes converged with their perceptions of the goal 
orientations of coaches and parents. The study also assessed the accuracy of young athletes' perceptions when compared to self reported goal orientations of their significant others.

A sample of swimmers ( $n=35$ males; $n=55$ females; $M=13.8$ years old $)$, coaches $(n=$ 10 ), and parents ( $n=24$ fathers; $n=47$ mothers) was used in the study. Swimmers were asked to identify the parent they perceived as most influential about their swimming beliefs and behaviors when deciding which parent would participate in the study (Givvin, 2001). To assess goal orientations, the athlete, parent, and coach were asked to complete the TEOSQ. Each athlete was also asked to fill out the TEOSQ twice more, in relation to their perception of the goal orientation of both their coach and parent respectively. To ascertain the athletes' perception of which significant other played a larger role in influencing their goal orientations, the athletes were asked as part of an interview to rate the influence of both coaches and parents on their swimming goals on a 5-point Likert scale.

Bivariate correlations were run to compare perceptions of significant others' goal orientations and those of the athletes. Task orientations of the athletes were highly correlated with the perception of task orientations in both coaches $(r=0.55, p<0.001)$ and parents $(r=$ $0.59, p<0.001)$. The findings were similar for ego orientation; with athletes self-reported ego orientation being correlated with the perception of ego orientations for both coaches $(r=0.72, p$ $<0.001)$ and parents $(r=0.61, p<0.001)$.

When comparing coaches' and parents' self-reported goal orientations with the youth athletes' perceptions of their goal orientations, only the relationship between ego orientation in coaches was found to be correlated $(r=0.22, p<0.05)$. This matches with athletes' reports of which significant other influenced their goal orientations more, with coaches being reported as significantly greater influence $(t(21)=2.82, p<0.02$; Givvin, 2001). 
Possible explanations for these findings include the idea that coaches have a broad influence over the entire team, and their goal orientations could have greater impact on individuals through reinforcement from their peers on the team (Givvin, 2001). It is also possible that the coach, being perceived as the most knowledgeable adult in the swimming context, has a greater opportunity to communicate their goal orientations to athletes in the sport setting.

Vazou, Ntoumanis, and Duda (2006) investigated the effects of perceived peer- and coach-created motivational climate on self-worth, enjoyment, trait anxiety, and exerted effort in a sample of youth athletes. The participants were 124 females and 369 males $(M=14.08$ years old). Coach-created motivational climate was measured using the PMCSQ-2. Peer-created motivational climate was assessed using the Peer Motivational Climate in Youth Sport Questionnaire (PeerMCYSQ). To measure enjoyment, trait anxiety, and self-worth, the InterestEnjoyment subscale of the Intrinsic Motivation Inventory, the Sport Anxiety Scale, and the Physical Self-Worth scale from the Children Physical Self-Perception Profile, were used respectively. In order to assess effort, coaches and physical education teachers were asked to rate their athlete's behavior using an altered version of the Teacher Rating of Academic Achievement Motivation Questionnaire.

The main hypothesis outlined by Vazou (2006) and colleagues was that athletes' perceptions of coach-created mastery climates would be positively related to physical self-worth, enjoyment and effort, while ego-oriented coach-created climates would be positively related to trait anxiety. Consistent with previous research and the hypotheses, Vazou (2006) and colleagues found that athletes who perceived higher levels of mastery oriented climate reported higher levels of enjoyment, effort, and physical self-worth. It is important to note that peer-created motivational climate was a stronger predictor of enjoyment, and the only significant predictor of 
physical self-worth. This study provided additional support for achievement goal theory and its validity when applied to youth sport settings.

The research investigating the relationship between parent-initiated and coach-created motivational climate and athlete achievement goal orientation has provided a certain number of insights. The literature reviewed above has helped to strengthen the suggestion that there is a connection between perceptions of parent-initiated motivational climate and athletes' achievement goal orientations (White, 1996; White 1998), and the relationship between coachcreated motivational climate and athletes' achievement goal orientations (Smith et al., 2009; Williams, 1998). Furthermore, Smoll (2007) and colleagues displayed that through an intervention (i.e., the MAC) geared at helping coaches promote a mastery climate, athletes' achievement goal orientations could be significantly altered. Overall, the literature suggests that motivational climate provides a viable pathway to understanding and potentially altering an athlete's achievement goal orientation.

\section{$\underline{\text { Conclusion }}$}

There have been a number of studies done to investigate the relationship between youth athletes and their significant others. This literature review focused on the influence that parents and coaches have on achievement goal orientation and motivational climate in the youth sports setting. The results of these studies have been equivocal in their findings, with some researchers suggesting that parents have the opportunity to influence the youth sport experience while others have stated that goal orientations are primarily dispositional and resistant to change. 
Additional research needs to be conducted in an effort to fully characterize the relationship between coaches, parents and the youth athlete with respect to achievement goal orientations and motivational climate. 


\section{References}

Ames, C. (1992). Classrooms: Goals, structures, and student motivation. Journal of Educational Psychology, 84(3), 261-271.

Babkes, M. L., \& Weiss, M. R. (1999). Parental influence on children's cognitive and affective responses to competitive soccer participation. Pediatric Exercise Science, 11(44), 62.

Barnett, N. P., Smoll, F. L., \& Smith, R. E. (1992). Effects of enhancing coach-athlete relationships on youth sport attrition. The Sport Psychologist, 6, 111-127.

Bergin, D. A., \& Habusta, S. F. (2004). Goal orientations of young male ice hockey players and their parents. The Journal of Genetic Psychology, 165(4), 383-397.

Black, S. J., \& Weiss, M. R. (1992). The relationship among perceived coaching behaviors, perceptions of ability, and motivation in competitive age-group swimmers. Journal of Sport \& Exercise Psychology, 14(3), 309-325.

Brustad, R. J. (1992). Integrating socialization influences into the study of children's motivation in sport. Journal of Sport \& Exercise Psychology, 14, 59-77.

Duda, J. L., \& Nicholls, J. G. (1992). Dimensions of achievement motivation in schoolwork and sport. Journal of Educational Psychology, 84(3), 290-299.

Ebbeck, V., \& Becker, S. L. (1994). Psychosocial predictors of goal orientations in youth soccer. Research Quarterly for Exercise and Sport, 65(4), 355. 
Fugligni, A. J., \& Eccles, J. S. (1993). Perceived Parent-Child Relationships and Early Adolescents' Orientation Towards Peers. Developmental Psychology, 29(4), 622-632.

Givvin, K. B. (2001). Goal orientations of adolescents, coaches, and parents: Is there a convergence of beliefs? The Journal of Early Adolescence, 21(2), 228-248.

Horn, T. S., \& Hasbrook, C. A. (1986). Psychological characteristics and the criteria children use for self-evaluation. Journal of Sport Psychology, 9, 208-211.

Nicholls, J. G. (1984). Achievement motivation: Conceptions of ability, subjective experience, task choice, and performance. Psychological Review, 91(3), 328-346.

Sage, L., \& Kavussanu, M. (2007). Multiple goal orientations as predictors of moral behavior in youth soccer. The Sport Psychologist, 21, 417-437.

Smith, R. E., Smoll, F. L., \& Cumming, S. P. (2009). Motivational climate and changes in young athletes' achievement goal orientations. Motivation and Emotion, 33, 173-183.

Smoll, F. L., \& Smith, R. E. (1989). Leadership behaviors in sport: A theoretical model and research paradigm. Journal of Applied Social Psychology, 19(18), 1522-1551.

Smoll, F. L., Smith, R. E., \& Cumming, S. P. (2007). Effects of a motivational climate intervention for coaches on changes in young athletes' achievement goal orientations. Journal of Clinical Sport Psychology, 1, 23-46. 
Vazou, S., Ntoumanis, N., \& Duda, J. L. (2006). Predicting young athletes' motivational indices as a function of their perceptions of the coach- and peer-created climate. Psychology of Sport and Exercise, 7, 215-233.

Waldron, J. J., \& Krane, V. (2005). Motivational climate and goal orientation in adolescent female softball players. Journal of Sport Behavior, 28(4), 378.

White, S. A. (1996). Goal orientation and perceptions of the motivational climate initiated by parents. Pediatric Exercise Science, 8, 122-129.

White, S. A. (1998). Adolescent goal profiles, perceptions of the parent-initiated motivational climate, and competitive trait anxiety. The Sport Psychologist, (12), 16-28.

Willams, L. (1998). Contextual influences and goal perspectives among female youth sport participants. Research Quarterly for Exercise and Sport, 69(1), 47-57.

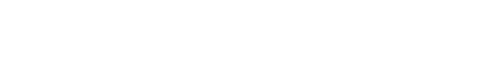

